\title{
Probing Multivalent Lectin-Carbohydrate Binding via Multifunctional Glycan-Gold Nanoparticles: Implications for Blocking Virus Infection
}

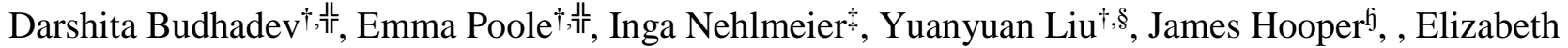 \\ Kalverda, ${ }^{\dagger}$ Uchangi Satyaprasad Akshath ${ }^{\dagger}{ }^{~ N i c o l e ~ H o n d o w}{ }^{\phi}$, W. Bruce Turnbull ${ }^{\dagger}$, Stefan Pöhlmann ${ }^{\ddagger}, *$ \\ Yuan Guo ${ }^{\mathfrak{f}, *}$, and Dejian Zhou ${ }^{\dagger, *}$ \\ $\dagger$ School of Chemistry and Astbury Centre for Structural Molecular Biology, University of Leeds, Leeds LS2 9JT, United \\ Kingdom. \\ *Infection Biology Unit, German Primate Center - Leibniz Institute for Primate Research, 37077 Göttingen, and Faculty of \\ Biology and Psychology, University of Göttingen, 37073 Göttingen, Germany. \\ $\S$ School of Pharmaceutical and Chemical Engineering, Chengxian College, Southeast University, Nanjing 210088, China. \\ ${ }^{5}$ School of Food Science \& Nutrition and Astbury Centre for Structural Molecular Biology, University of Leeds, Leeds LS2 \\ 9JT, United Kingdom. \\ $\phi$ School of Chemical and Process Engineering, University of Leeds, Leeds LS2 9JT, United Kingdom. \\ 少 These authors contributed equally to this work.
}

KEYWORDS. Gold nanoparticle, glycoconjugate, multivalent lectin-glycan interaction, fluorescence quenching, binding affinity, multi-modal readout, virus inhibition.

\begin{abstract}
Multivalent lectin-glycan interactions are widespread in biology and are often exploited by pathogens to bind and infect host cells. Glycoconjugates can block such interactions and thereby prevent infection. The inhibition potency strongly depends on matching the spatial arrangement between the multivalent binding partners. However, the structural details of some key lectins remain unknown and different lectins may exhibit overlapping glycan specificity. This makes it difficult to design a glycoconjugate that can potently and specifically target a particular multimeric lectin for therapeutic interventions, especially under the challenging in vivo conditions. Conventional techniques such as surface plasmon resonance (SPR) and isothermal titration calorimetry (ITC) can provide quantitative binding thermodynamics and kinetics. However, they cannot reveal key structural information, e.g. lectin's binding site orientation, binding mode, and inter-binding site spacing, which are critical to design specific multivalent inhibitors. Herein we report that gold nanoparticles (GNPs) displaying a dense layer of simple glycans are powerful mechanistic probes for multivalent lectin-glycan interactions. They can not only quantify the GNP-glycan-lectin binding affinities via a new fluorescence quenching method, but also reveal drastically different affinity enhancing mechanisms between two closely-related tetrameric lectins, DC-SIGN (simultaneous binding to one GNP) and DC-SIGNR (inter-crosslinking with multiple GNPs), via a combined hydrodynamic size and electron microscopy analysis. Moreover, a new term, potential of assembly formation (PAF) has been proposed to successfully predict the assembly outcomes based on the binding mode between GNP-glycans and lectins. Finally, the GNP-glycans can potently and completely inhibit DC-SIGN-mediated augmentation of Ebola virus glycoprotein-driven cell entry (with IC I $_{50}$ values down to $95 \mathrm{pM}$ ), but only partially block DC-SIGNR-mediated virus infection. Our results suggest that the ability of a glycoconjugate to simultaneously block all binding sites of a target lectin is key to robust inhibition of viral infection.
\end{abstract}

\section{Introduction}

Multivalent lectin-glycan interactions are widespread and mediate many important biological functions which include cellcell communication, pathogen-host cell recognition, attachment and infection, and modulation of immune responses. ${ }^{1-9}$ As most monovalent lectin-glycan binding events are often too weak to be bio-functional, many lectins form multimeric structures to cluster their carbohydrate-binding-domains (CRDs) for efficient binding with spatially matched multivalent glycans to enhance binding affinity and specificity. ${ }^{10-14}$ The overall multivalent affinity is not only directly linked to the monovalent affinity, but also the glycan valency and the mode of binding. In general, a pair of spatially matched multivalent binding partners can bind simultaneously with each other and form a single entity. This gives the highest affinity enhancement and selectivity due to the most favorable enthalpy and entropy terms. ${ }^{13}$ While those without such spatial and orientation match may intercrosslink with each other to maximize binding enthalpy and form large scale assemblies, but this typically gives lower affinity enhancement and binding specificity due to an unfavorable entropy penalty. ${ }^{15}$ Therefore, understanding the structural mechanism underlying the affinity enhancement in multivalent protein-ligand binding is key to the design of potent, specific multivalent inhibitors against a target multivalent receptor. Notably, the development of potent glycoconjugates to block virus binding and infection of host cells can prevent virus mutation and developing resistance, a unique advantage over other antiviral strategies. ${ }^{9}$

A number of different scaffolds, including DNAs, proteins, polymers, dendrimers, $\mathrm{C}_{60}$ derivatives, vesicles, and inorganic 
nanoparticles, have been employed to construct glycoconjugates $^{14,16-22}$ to study multivalent lectin-glycan recognition and develop effective interventions against certain diseases. Some of these have exhibited excellent potency in inhibiting pathogen infection. ${ }^{9,11,13-14,16-20,23-24}$ Most of the bindings have been evaluated by conventional biophysical techniques such as surface plasmon resonance (SPR), ${ }^{14,22}$ and/or isothermal titration calorimetry (ITC). ${ }^{14,25-27}$ Despite their wide use and good capacity in providing quantitative binding affinity, thermodynamic and kinetic data, these techniques cannot reveal key structural information of the target lectin, e.g. binding site orientation, interbinding site distance, and binding mode which are critical to design potent, specific multivalent glycan inhibitors. Meanwhile, the unique size-dependent physical properties of nanomaterials have been harnessed to study lectin-glycan interactions. A good example here are gold nanoparticles (GNPs) ${ }^{28}$ whose strong, size- and aggregation-state dependent absorption, ${ }^{29-30}$ powerful signal amplification in SPR, ${ }^{31}$ and surface enhanced Raman scattering ${ }^{32-33}$ have been widely exploited for biosensing and diagnostic applications. Despite these successes, glycan conjugated GNPs (GNP-glycans) have not been exploited as new structural and mechanistic probes for multivalent lectin-glycan interactions.

Recently, we have shown that $\mathrm{CdSe} / \mathrm{ZnS}$ quantum dots (QDs) displaying a dense layer of mannose glycans are powerful structural probes for multivalent lectin-glycan binding. ${ }^{34-36}$ The QD probes can not only quantify the binding affinity via a ratiometric FRET readout but also dissect the different binding modes between a pair of closely-related, almost identical tetrameric lectins, DC-SIGN ${ }^{37-38}$ and DC-SIGNR ${ }^{39}$ (collectively abbreviated as DC-SIGN/R hereafter). DC-SIGN/R are important lectin receptors which play a key role in facilitating the HIV, Ebola virus and Zika virus infections. ${ }^{34-35,40-41}$ Moreover, DC-SIGN is also key to immune regulation, ${ }^{1,5,42-43}$ making it an highly attractive target for developing immunotherapies against important human diseases such as cancer, allergy, and autoimmune diseases. ${ }^{1,42,44}$ However, its tetrameric structure remains unknown, making it difficult to develop novel glycoconjugates that can potently and specifically target DC-SIGN for therapeutic interventions, especially when the overlapping glycan specificity of various lectins is considered. ${ }^{1}$ Using the QD-glycans, we have found that DC-SIGN's 4 CRDs bind simultaneously to one QD and give an impressive affinity enhancement factor $(\beta)$ of up to 1.5 million fold over the corresponding monovalent binding. The QD-glycans also potently inhibit DC-SIGNmediated augmentation of Ebola virus entry into host cells with sub-nM IC $_{50}$ values. ${ }^{35}$ Despite such success, the cytotoxicity and long term toxicity of the CdSe QD scaffold has significantly limited its potential use as DC-SIGN targeting therapeutic agents, especially under in vivo conditions.

To address this issue, here we have constructed polyvalent glycan-nanoparticle probes on a $5 \mathrm{~nm}$ (diameter) GNP scaffold to take the advantages of GNPs' excellent biocompatibility, low-/non-toxicity, and robust gold-thiol surface chemistry for easy control of the glycan density and surface presentation. ${ }^{28}$ Moreover, after coating with lipoic acid (LA) based glycan ligands containing a terminal $\alpha$-mannose (Man) or $\alpha$-mannose$\alpha-1,2$-mannose (DiMan), the GNP-glycans are of the similar size and mannose glycan coating to gp120 trimer, ${ }^{45-46}$ the HIV surface densely glycosylated glycoprotein which is responsible for initiating HIV-DC-SIGN interaction to facilitate HIV infection. Thus, the GNP-glycans are good mimics of gp120 for probing its interaction with DC-SIGN. Using DC-SIGN/R as model lectins, we show that the GNP's strong fluorescent quenching property ${ }^{47}$ can be exploited as a reliable method to quantify multivalent GNP-glycan-lectin binding for the $1^{\text {st }}$ time. Moreover, its nanoscale size, and high contrast under electron microscopy imaging have been integrated into a multimodal readout to reveal the different binding modes and affinity enhancement mechanisms for DC-SIGN/R (e.g. simultaneous binding for DC-SIGN, but inter-crosslinking for DC-SIGNR). Furthermore, the GNP-lectin binding modes are found to be directly linked to the GNP's ability to block lectin mediated virus infection of host cells: only a GNP-glycan which binds simultaneously to all binding sites of the target lectin can potently and completely block virus infection, but not that showing a cross-linking binding mode.

\section{Results and Discussion}

Ligand design and synthesis. The schematic structures of the GNP-glycan conjugates and the chemical structures of the glycan ligands used in this study are shown in Figure 1.

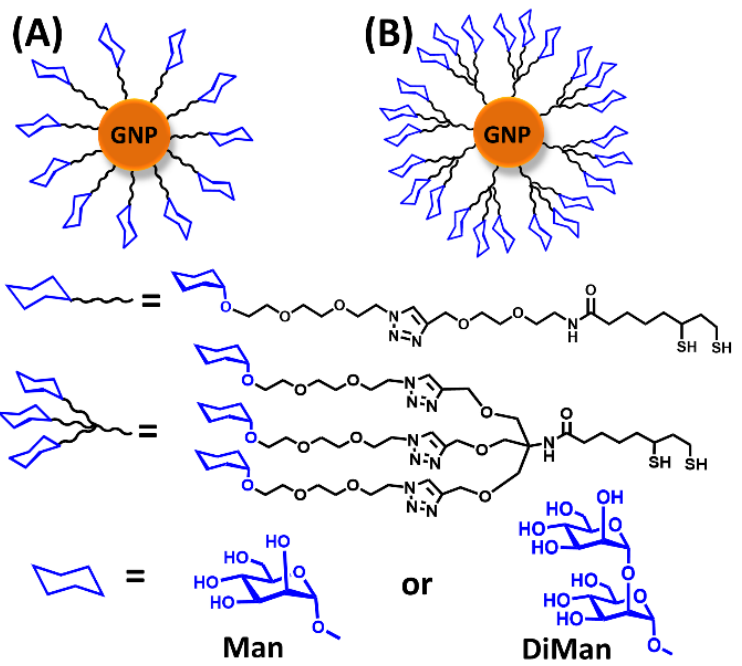

Figure 1. Schematic of the GNP-glycans used in this study. The GNP is coated with DHLA-based glycan ligand containing either one (A) or three (B) terminal $\alpha$-1-mannose or $\alpha$-1-mannose- $\alpha-1,2$ mannose to tune its surface glycan valency. The chemical structures of glycan ligands are depicted underneath.

Each ligand contains three unique functional domains, a dihydrolipoic acid (DHLA) for strong binding to the GNP surface via the formation of 2 strong Au-S bonds to impose excellent stability; ${ }^{48}$ a short, flexible oligo-(ethylene glycol) linker to enhance water solubility, and to resist non-specific adsorption, ${ }^{35}$, 49 and a terminal an $\alpha-1$-mannose or $\alpha$-1-mannose- $\alpha-1,2-$ mannose (abbreviated as DHLA-Man or DHLA-DiMan, respectively, hereafter) for specific binding to DC-SIGN/R. ${ }^{34-35} \mathrm{We}$ have found previously that DC-SIGN binds more efficiently to QDs capped with higher mannose densities. ${ }^{34}$ Moreover, glycoconjugates with higher glycan valency have often shown to exhibit better virus inhibition potencies. ${ }^{9,14,16,21,50}$ Thus we are interested to study whether GNP-glycans' DC-SIGN/R binding affinity and virus inhibition potency can be further enhanced by increasing its surface glycan density. Thus, a branched version of the DHLA-glycan ligand, each containing three terminal glycans, are also synthesized (denoted as DHLA-(Man) $)_{3}$ or DHLA$(\text { DiMan })_{3}$, respectively). ${ }^{50}$ The branched ligands have the same DHLA anchoring group for GNP binding as the monomeric glycans. Thus, a similar number of ligands are expected to coat 
each GNP, allowing us to prepare more densely glycosylated GNPs as shown schematically in Figure 1.

\section{Scheme 1. Synthetic route to LA-Man-/DiMan ligands}

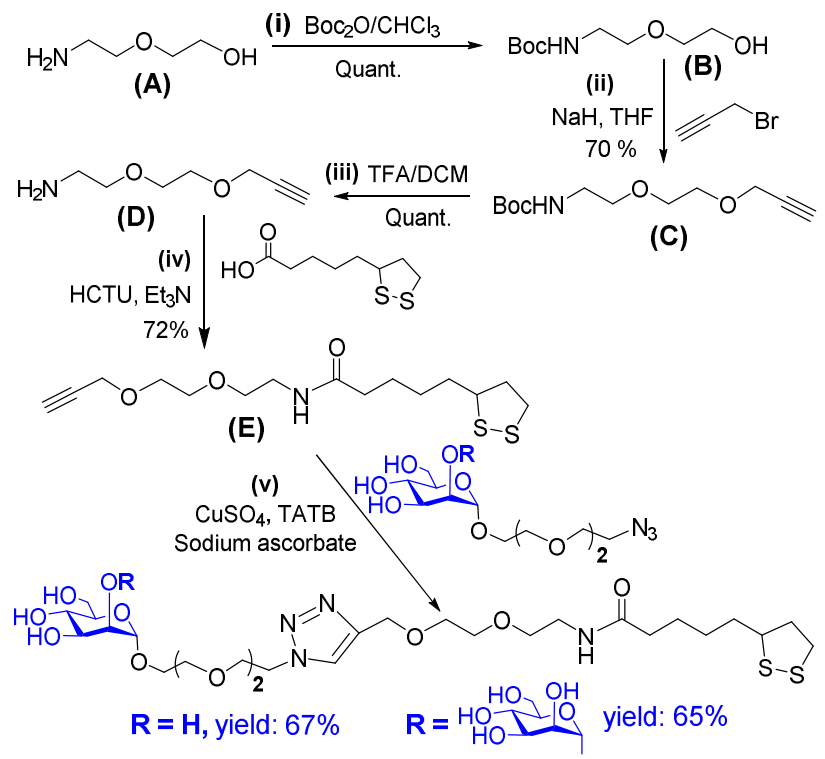

Scheme 2. Synthetic route to LA-(Man) $)_{3} /\left(\right.$ DiMan $_{3}$ ligands

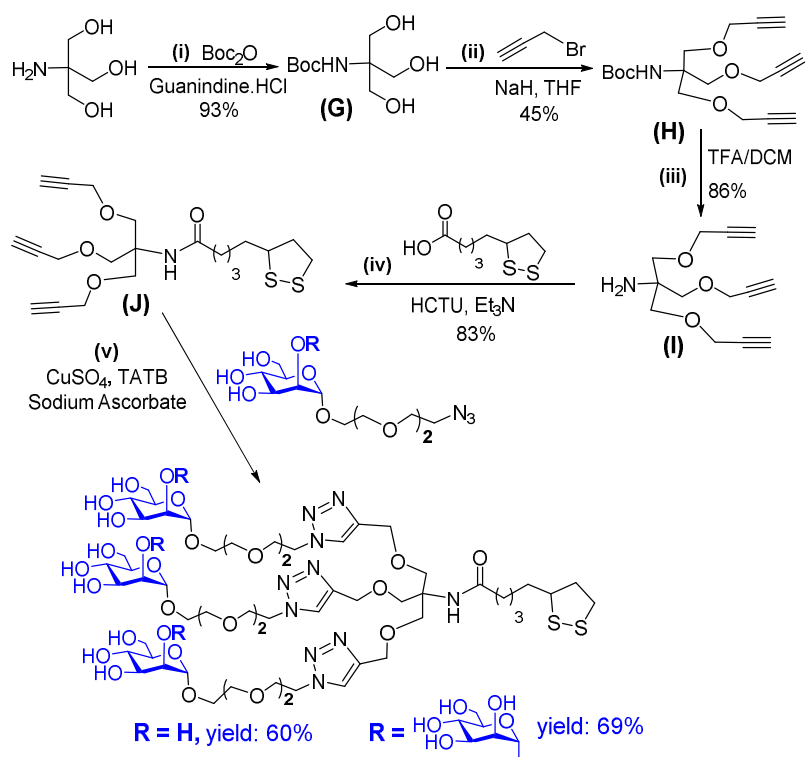

The synthetic routes to the monomeric LA-glycan and branched trimeric LA-(glycan) 3 ligands are shown in Schemes 1 and 2, respectively. First, the LA based linker molecules each containing one or three terminal acetylene groups were synthesized in good yields using the standard BOC protection and amide coupling chemistries. Details of the synthetic procedures and spectroscopic data of the intermediate compounds were provided in the Supporting Information (SI). Second, $\alpha$-mannose and $\alpha$ mannose- $\alpha-1,2$-mannose appending a hydrophilic di(ethylene glycol)-azide linker $\left(\mathrm{N}_{3}-\mathrm{EG}_{2}-\mathrm{Man}-/ \mathrm{DiMan}\right)$ to provide some flexibility to the terminal glycans were synthesized using our established procedures. ${ }^{34-35}$ Third, the LA-acetylene linkers were coupled efficiently to $\mathrm{N}_{3}-\mathrm{EG}_{2}$-Man/DiMan via the $\mathrm{Cu}$-catalyzed click chemistry ${ }^{16}$ to give the desired LA-Man/DiMan or LA-(Man) ${ }_{3} /(\text { DiMan })_{3}$ ligands (see Experimental Section for the general procedures and spectroscopic data, and SI for their ${ }^{1} \mathrm{H}$ and ${ }^{13} \mathrm{C}$ NMR spectra). Finally, the LA-glycan ligands were reduced quantitatively to their corresponding DHLA forms by tris (2-carboxyethyl)phosphine hydrochloride (TCEP.HCl) $)^{51-52}$ before they were used to prepare the GNP-glycans.

GNP-glycan preparation. GNP-glycans (GNP capped with the DHLA-glycan ligands) were prepared by incubation of a 5 $\mathrm{nm}$ citrate stabilized GNP with the above DHLA-glycan ligands in water at a ligand:GNP molar ratio of 1000:1 for $24 \mathrm{~h}$. Any free unbound ligands were removed by ultra-filtration using $30 \mathrm{~K}$ MWCO filter tubes and washing with pure water. GNPglycans prepared using LA-glycans or their reduced DHLAglycan forms were found to be identical in terms of hydrodynamic sizes and stability. Thus the air-stable LA-glycan ligands could be directly used to make the GNP-glycans, eliminating the need of reduction and handling air-sensitive DHLA-glycan ligands that were essential in QD-glycan preparation via capexchange. ${ }^{34,40,48}$ This made the GNP-glycan preparation simple and straightforward. This result was fully consistent with earlier literature reports that dialkyldisulfides were cleaved upon binding to gold surfaces, forming identical self-assembled monolayers to their alkylthiol counterparts. ${ }^{53}$ The GNP-glycans were highly stable, no changes of physical appearance or precipitation were observed after prolonged storage ( $>6$ months) in a fridge. They were uniform and monodisperse in both water and in a binding buffer $(20 \mathrm{mM}$ HEPES, $100 \mathrm{mM} \mathrm{NaCl}, 10 \mathrm{mM}$ $\left.\mathrm{CaCl}_{2}, \mathrm{pH} 7.8\right)$ with hydrodynamic diameters $\left(\mathrm{D}_{\mathrm{h}} \mathrm{s}\right)$ of $\sim 11 \mathrm{~nm}$ (see SI, Figure $\mathrm{S} 1$ and Table $\mathrm{S} 1$ ). Such $\mathrm{D}_{\mathrm{h}}$ values matched well to the size of gp120 trimer $(\sim 12 \mathrm{~nm}) .{ }^{45}$ Moreover, the GNPs were densely coated with mannose containing glycans similar to those found on gp120 surface. Using the ligand amount difference between that used and that remained in the supernatant after conjugation (measured by a phenol-sulfuric acid assay), ${ }^{35}$ the numbers of ligands bound on each GNP were estimated as $\sim 490, \sim 690,720$, and $\sim 650$ for LA-Man, LA-DiMan, LA$(\mathrm{Man})_{3}$ and LA-(DiMan) ${ }_{3}$, respectively. Using the $\mathrm{D}_{\mathrm{h}}$ values and the method reported by the Mirkin group,${ }^{54}$ the average interglycan distances were estimated as $\sim 0.97, \sim 0.83, \sim 0.46$, and $\sim 0.49 \mathrm{~nm}$ for GNP-Man, GNP-DiMan, GNP-(Man) ${ }_{3}$ and GNP$(\text { DiMan })_{3}$, respectively (SI, Table S2). The average inter-glycan distances of GNP-Man/DiMan fell well within the majority of inter-glycan sequon distances (e.g. 0.7-1.3 nm) found on gp120 ${ }^{46}$ but those of GNP-(Man/Diman $)_{3}$ were considerably smaller. These results suggested that the GNP-Man/DiMan could act as good mimics of gp120 for probing its DC-SIGN interaction.

Quantifying GNP-glycan-DC-SIGN/R binding affinity. Besides strong plasmonic absorption, GNPs are well-known for their strong and universal fluorescence quenching property. ${ }^{47}$ Moreover, its quenching has shown to follow the nano-surface energy transfer (NSET), ${ }^{55-56}$ rather than Förster resonance energy transfer (FRET) mechanism. As a result, its quenching is more superior and covers a longer distance range than most organic quenchers relying on the FRET mechanism. ${ }^{47,55}$ Indeed, the GNP's superior quenching ability has been widely exploited for biosensing applications, ${ }^{57-58}$ but not as a readout method for lectin-glycan binding quantification. Here the GNP's outstanding fluorescence quenching was exploited as a new readout for multivalent lectin-glycan binding quantification for the first time (Figure 2A). To do this, we first introduced a cysteine sitespecifically on the CRD (outside its glycan binding pocket so not affecting its glycan binding properties) of DC-SIGN/R extracellular segments by mutagenesis. The mutant proteins have shown to retain faithfully the tetrameric structure and glycan binding properties of wildtype proteins. ${ }^{34-35} \mathrm{We}$ then labeled the 
proteins using a maleimide modified Atto-594 and confirmed the labeling by high resolution mass spectroscopy (SI, Figure S2). We then recorded the fluorescence spectra of labeled DCSIGN/R without and with each GNP-glycan under a fixed protein:GNP molar ratio of 1:1 over a concentration range of 0-64 $\mathrm{nM}$. All binding studies were carried out in a binding buffer containing a large excess of bovine serum albumin (BSA, 1 $\mathrm{mg} / \mathrm{mL}$ final concentration). The inclusion of large excesses of BSA, a non-target serum protein of high abundance in vivo, in binding studies made the conditions resemble more closely to real biological situations. Moreover, this also greatly reduced non-specific interactions and adsorption of proteins and GNPs to surfaces (a main source of experimental errors at low concentrations, e.g. $<10 \mathrm{nM}){ }^{59}$

The typical fluorescence spectra showing the binding between DC-SIGN and GNP-DiMan were given in Figure 2B. In the absence of GNP-DiMan, DC-SIGN's fluorescence intensity was found to increase linearly with concentration. While in the presence of GNP-DiMan, its fluorescence was greatly reduced and increasingly deviated from the linear relationship with the increasing concentration (SI, Figure S3). This result was fully consistent with that, with the increasing concentration, an increasing proportion of DC-SIGN were bound to and quenched by GNP-DiMan in close proximity. The specificity of DCSIGN-GNP-DiMan binding was verified by two controls: (1) mixing DC-SIGN with a GNP capped with a control DHLA$\mathrm{EG}_{2}-\mathrm{OH}$ ligand lacking the terminal glycan produced negligible quenching; (2) free mannose could effectively compete with GNP-DiMan binding to DC-SIGN, leading to a significant, dose-dependent fluorescence recovery (SI, Figure S4).
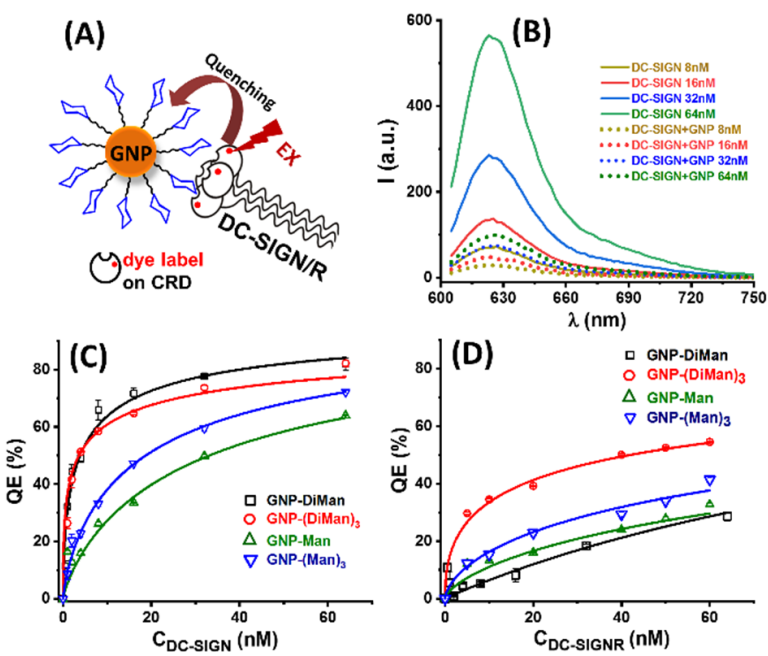

Figure 2. (A) Schematic showing the quenching of DC-SIGN/R (dye-labeled) fluorescence upon binding to a GNP-glycan, which acts as a readout for binding quantification. (B) Typical fluorescence spectra of varied concentrations of DC-SIGN without (solid lines) and with (broken lines) 1 molar equivalent of GNP-DiMan $\left(\lambda_{\mathrm{EX}}=590 \mathrm{~nm}\right)$. $(\mathbf{C}, \mathbf{D})$ The quenching efficiency $(\mathrm{QE} \%)-$ concentration relationship for DC-SIGN (C) or DC-SIGNR (D) binding to the various GNP-glycans fitted by the Hill's equation.

To analyze the binding data quantitatively, we first calculated the quenching efficiency $(\mathrm{QE})$ at each concentration $(C)$ via:

$$
\mathrm{QE} \%=\left(\mathrm{IF}_{0}-\mathrm{IF}\right) / \mathrm{IF}_{0} \times 100 \%
$$

Where $\mathrm{IF}_{0}$ and IF are the integrated fluorescence of the protein in the absence and presence of each GNP-glycan, respectively. Given that the fluorescence of DC-SIGN/R increases linearly with $C$ in the absence of GNP-DiMan (SI, Figure S3), and GNPs can completely quench various fluorophores at close proximity (e.g. > 99.9\%), ${ }^{47}$ the $\mathrm{QE} \%$ thus faithfully represents the percentage of proteins bound to the GNP-glycan. Thus, the apparent binding dissociation constant $\left(\mathrm{K}_{\mathrm{d}}\right)$ can be derived from the $\mathrm{QE}-$ $C$ relationship by fitting with Hill's equation:

$$
\mathrm{QE}=\mathrm{QE}_{\max } \times \mathrm{C}^{\mathrm{n}} /\left(\mathrm{K}_{\mathrm{d}}{ }^{\mathrm{n}}+\mathrm{C}^{\mathrm{n}}\right)
$$

Where $\mathrm{QE}_{\max }, \mathrm{K}_{\mathrm{d}}, C$, and $\mathrm{n}$ are the maximum $\mathrm{QE}$ (fixed at 100), apparent binding dissociation constant, protein concentration, and Hill coefficient, respectively.

Table 1. Summary of the fitting parameters of DC-SIGN/R binding to various GNP-glycans derived from Figures 2C/D.

\begin{tabular}{|l|c|c|c|}
\hline GNP-glycan + Protein & $\mathbf{K}_{\mathbf{d}}(\mathbf{n M})$ & $\boldsymbol{n}$ & $\mathbf{R}^{\mathbf{2}}$ \\
\hline GNP-Man + DC-SIGN & $33.1 \pm 2.1$ & $0.82 \pm 0.07$ & 0.997 \\
\hline GNP-(Man) 3 + DC-SIGN & $18.7 \pm 0.3$ & $0.77 \pm 0.01$ & 0.999 \\
\hline GNP-DiMan + DC-SIGN & $3.9 \pm 0.3$ & $0.59 \pm 0.03$ & 0.999 \\
\hline GNP-(DiMan) 3 + DC-SIGN & $3.6 \pm 0.1$ & $0.42 \pm 0.01$ & 1.00 \\
\hline GNP-Man + DC-SIGNR & $214 \pm 68$ & $0.68 \pm 0.10$ & 0.994 \\
\hline GNP-(Man) 3 + DC-SIGNR & $133 \pm 20$ & $0.63 \pm 0.07$ & 0.996 \\
\hline GNP-DiMan + DC-SIGNR & $152 \pm 37$ & $0.99 \pm 0.14$ & 0.954 \\
\hline GNP-(DiMan) 3 + DC-SIGNR & $42 \pm 2$ & $0.48 \pm 0.03$ & 0.999 \\
\hline
\end{tabular}

Figures 2B and 2C showed the best fits of the QE- $C$ relationships for DC-SIGN/R binding to each GNP-glycan. The resulting fitting parameters were summarized in Table 1. Four key points could be drawn from the binding data given in Table 1. (1) DC-SIGN bound more strongly to GNP-glycans than DCSIGNR did. This effect was particularly pronounced for GNPDiMan where the binding affinity difference was as high as $\sim 40$ fold. As GNP-DiMan here presented a good mimic of gp120, its stronger binding affinity with DC-SIGN over DC-SIGNR could thus help explain why DC-SIGN was found more effective than DC-SIGNR in transmitting infections for some HIV strains. ${ }^{60}$ This result also agreed well with those reported previously with QD-glycans where the binding $\mathrm{K}_{\mathrm{d}} \mathrm{S}$ were measured ratiometrically via FRET. $^{34}$ Given that the CRDs in DCSIGN/R had the same mannose binding motifs ${ }^{61}$ the difference here indicated that DC-SIGN/R might adopt different modes in binding to GNP-glycans, similar to those observed with QDglycans. ${ }^{35}$ (2) Further increasing the GNP surface glycan density via capping with the dendritic LA-(glycan) $)_{3}$ ligands significantly improved the binding affinity with DC-SIGNR (e.g. $\mathrm{K}_{\mathrm{d}}$ $\sim 42$ v.s. $\sim 152 \mathrm{nM}$, or 3.6 fold enhancement for GNP-(DiMan) v.s. GNP-DiMan), but not much with DC-SIGN, suggesting that DC-SIGNR may prefer binding to GNPs with even higher glycan densities. (3) Low $\mathrm{nM} \mathrm{K}_{\mathrm{d}}$ (e.g. $3.9 \mathrm{nM}$ ) for DC-SIGN binding with GNP-DiMan was obtained, which was $\sim 250,000$ fold tighter than the corresponding monomeric binding between $\mathrm{Di}$ Man and DC-SIGN CRD $\left(\mathrm{K}_{\mathrm{d}}=0.9 \mathrm{mM}\right){ }^{25}$ suggesting that a polyvalent display of the glycans on the GNP greatly enhanced its multivalent binding affinity with DC-SIGN. These results were fully consistent with those reported for other multivalent lectin-glycoconjuagte interactions..$^{10,14,18,22}$ (4) A higher degree of affinity enhancement was observed for DC-SIGN binding to GNP-DiMan over GNP-Man, possibility due to the former being able to exploit more efficiently the CRD's secondary glycan 
bind sites than the later. ${ }^{61}$ Overall, these results agreed well with those reported previously with the QD-glycans. ${ }^{35}$

Probing DC-SIGN/R-GNP-glycan binding mode and affinity enhancing mechanism. First we monitored the $\mathrm{D}_{\mathrm{h}} \mathrm{S}$ of GNPDiMan before and after binding to wildtype DC-SIGN/R (unlabeled) by dynamic light scattering (DLS). ${ }^{62}$ GNP-DiMan displayed a single $D_{h}$ species of $\sim 11 \mathrm{~nm}$ with a narrow distribution (full width at half maximum, FWHM $=3.5 \mathrm{~nm}$, Figure 3A1) in the binding buffer. After mixing with DC-SIGN (protein: GNP molar ratio $=20: 1)$, the size of the dominate species was significantly increased $\left(D_{h}=\sim 41 \mathrm{~nm}\right)$ and broadened (FWHM $\sim 28$ $\mathrm{nm}$, Figure 3A2). This result was consistent with that expected for each GNP-glycan being bound by a limited number of DCSIGN molecules, forming a protein shell on the GNP. In contrast, mixing DC-SIGNR with GNP-DiMan produced a dominant species whose $\mathrm{D}_{\mathrm{h}}$ was gradually increased from $c a .300$ to $>2000 \mathrm{~nm}$ over a period of $4 \mathrm{~h}$ (Figure 3A3). Such sizes were clearly too big to be individual GNP-DC-SIGNR assemblies, a strong indication of macroscopic assembly, arising presumably from DC-SIGNR and GNP-DiMan inter-crosslinking.
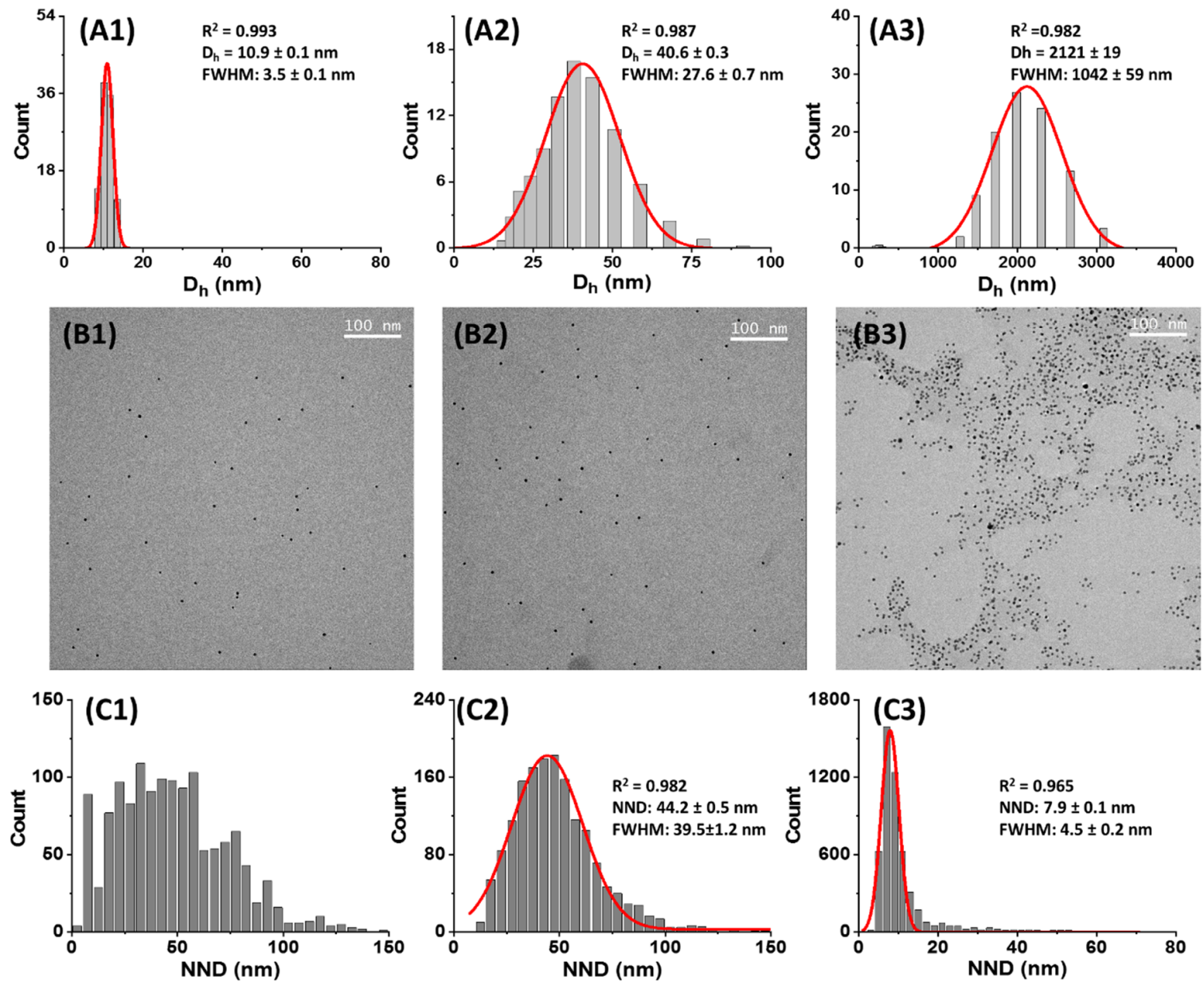

Figure 3. Typical $D_{h}$ distribution histograms of GNP-DiMan only (10 nM, A1); GNP-DiMan (10 nM) + wildtype DC-SIGN (200 nM, A2) or GNP-DiMan (16 nM) + wildtype DC-SIGNR (640 nM, A3). TEM images of cryo-prepared samples of GNP-DiMan only (40 nM, B1), GNP-DiMan $(40 \mathrm{nM})+$ DC-SIGN $(1.5 \mu \mathrm{M}, \mathbf{B 2})$ or GNP-DiMan $(40 \mathrm{nM})+$ DC-SIGNR $(1.5 \mu \mathrm{M}, \mathbf{B 3})$, and their corresponding GNP nearest neighbor distance (NND) histograms $(\mathbf{C 1}, \mathbf{C 2}, \mathbf{C 3})$. The red curves show the Guanssian fits of the histograms.

This assumption was verified by transmission electron microscopy (TEM) imaging of cryo-prepared GNP-DiMan-protein samples via rapid plunge freezing followed by vacuum drying which we had shown previously to preserve the native dispersion states of nanoparticle solutions. ${ }^{63}$ In the absence of DCSIGN/R, GNP-DiMan appeared as isolated single particles (Figure 3B1) and gave a randomly distributed nearest neighbor distance (NND) over a range of 10 to $100 \mathrm{~nm}$ (Figure 3C1). Binding of DC-SIGN with GNP-DiMan also gave isolated single particles (Figure 3B2), although the resulting NND distribution histogram could be fitted well $\left(\mathrm{R}^{2}=0.982\right)$ by a single
Gaussian distribution to yield an average NND of $\sim 44 \mathrm{~nm}$ (Figure 3C2). Interestingly, this NND value matched well to the $D_{h}$ size of GNP-DiMan-DC-SIGN assembly ( 41 nm), suggesting that the formation of a layer of DC-SIGN on the GNP prevented individual GNPs from coming close to each other. In contrast, binding of DC-SIGNR with GNP-DiMan produced large scale, closely-packed GNP assemblies of hundreds of nm cross (Figure 3B2) with a rather small NND of $\sim 7.9 \mathrm{~nm}$ (Figure 3C3). This result agreed well with the DLS measurement, confirming that binding of DC-SIGNR led to macroscopic assemblies of GNPs via DC-SIGNR-GNP-DiMan intercross linking. These 
results revealed that the binding modes of DC-SIGN/R to GNPDiMan were clearly different: DC-SIGN must have bound simultaneously to one GNP-DiMan via all of its four binding sites and formed a layer of proteins surrounding each GNP, giving rise to isolated single particles. In contrast, DC-SIGNR and polyvalent GNP-DiMan inter-crosslinked each other, and formed large scale but closely-packed GNP-DC-SIGNR assemblies. Therefore, by harnessing GNPs' nanoscale size and high contrast under TEM imaging, we have developed a new multimodal readout which successfully dissected the distinct modes of GNP-DiMan in binding to DC-SIGN/R. This result agreed fully with those reported previously with QD-glycans. ${ }^{35}$

The distinct binding modes exhibited by DC-SIGN/R could also help explain their different affinities with GNP-glycans. For DC-SIGN, its simultaneous binding with one GNP via all 4 of its CRDs should yield strong affinity enhancement from both the favorable enthalpy and entropy terms. For DC-SIGNR, whilst its inter-crosslinking mode of binding with GNP-glycans could maximize the binding enthalpy, the resulting large scale assemblies would incur significant entropy penalty. As a result, DC-SIGN should bind more strongly to GNP-glycans than DCSIGNR did, matching well to the apparent $\mathrm{K}_{\mathrm{d}}$ data measured by fluorescence quenching (Table 1).

Correlation between lectin-GNP-glycan affinity and assembly. The credibility of this GNP quenching based affinity measurement method was further verified by the DLS data. For example, binding of an increasing amount of DC-SIGN to a fixed amount of GNP-DiMan $(10 \mathrm{nM})$ gave a more rapid increase of $D_{h}$ than that to GNP-Man (Figure 4A), consistent with the former being a stronger binding partner than the latter (apparent $\mathrm{K}_{\mathrm{d}}$ : 3.9 v.s. $33 \mathrm{nM}$ ). Moreover, mixing an increasing amount of DC-SIGNR with GNP-(Man) $)_{3}$ yielded no noticeable $D_{h}$ changes throughout the concentration range studied (20-200 $\mathrm{nM}$ ), indicating no measurable binding (Figure 4B). While mixing DC-SIGNR with GNP-(DiMan) 3 also produced no apparent $\mathrm{D}_{\mathrm{h}}$ changes initially $(\leq 100 \mathrm{nM})$; as DC-SIGNR concentration was increased further, a dramatic increase of $\mathrm{D}_{\mathrm{h}}$ was observed, particularly at $200 \mathrm{nM}$, a clear indication of the formation of large scale GNP-DC-SIGNR assemblies (see Figure 4B, and SI, Figures. S5-S8).
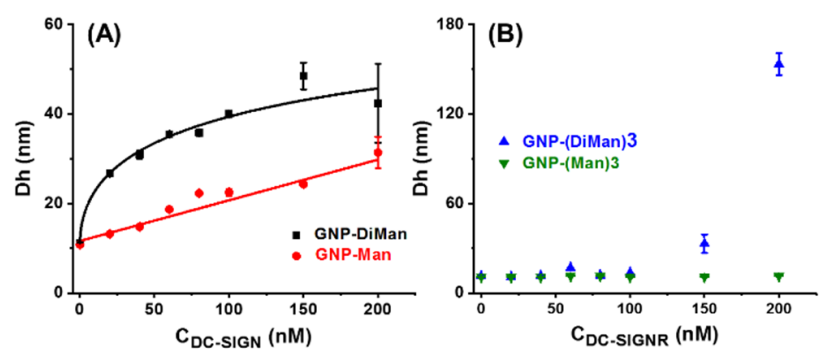

Figure 4. $\mathrm{Dh}_{\mathrm{h}} \mathrm{C}_{\text {protein }}$ relationships for GNP-glycan (10 nM) binding to wildtype DC-SIGN/R at different concentrations. (A) DC-SIGN binding to GNP-DiMan (black squares, data fitted by Hill's equation: $\mathrm{Y}=\mathrm{a}+(\mathrm{b}-\mathrm{a}) \times \mathrm{X}^{\mathrm{n}} /\left(\mathrm{k}^{\mathrm{n}}+\mathrm{X}^{\mathrm{n}}\right)$; where $\mathrm{a}=11.1 \pm 0 \mathrm{~nm} ; \mathrm{b}=80 \pm 99$ $\mathrm{nm} ; \mathrm{k}=200 \pm 990 \mathrm{nM}$ and $\mathrm{n}=0.53 \pm 0.36, \mathrm{R}^{2}=0.997$ ) or GNP-Man (red dots, data fitted by a linear relationship, $\mathrm{Y}=\mathrm{a}+\mathrm{b} \times \mathrm{X}$; where $\left.\mathrm{a}=11.6 \pm 0.7 \mathrm{~nm} ; \mathrm{b}=0.091 \pm 0.010, \mathrm{R}^{2}=0.928\right) ;(\mathbf{B})$ DC-SIGNR binding to GNP-(DiMan)3 (blue triangles) or GNP-(Man)3 (green triangles).

To provide a more quantitative explanation of the data, here we introduced a new term: the potential of assembly formation (PAF):

$$
\mathrm{PAF}=\mathrm{C}_{0(\mathrm{GNP})} \times \mathrm{C}_{0(\text { protein })} /\left(\mathrm{K}_{\mathrm{d}}\right)^{2}
$$

Where $\mathrm{C}_{0(\mathrm{GNP})}, \mathrm{C}_{0 \text { (protein) }}$ and $\mathrm{K}_{\mathrm{d}}$ are GNP-glycan and protein starting concentrations and their apparent binding $\mathrm{K}_{\mathrm{d}}$, respectively. As $\mathrm{K}_{\mathrm{d}}$ indicates $50 \%$ binding at equilibrium, the PAF thus represents the ratio of a reaction quotient to equilibrium of a reversible binding reaction. Where $\mathrm{PAF}=1$ would indicate equilibrium $(50 \%)$ binding, while PAF $>1$ indicates binding being favorable and PAF $>10$ being strongly favorable $(>90 \%)$. Similarly, PAF $<1$ indicates binding being unfavorable and PAF $<0.1$ being strong unfavorable $(<10 \%$ binding).

Using this definition and the apparent $\mathrm{K}_{\mathrm{d}} \mathrm{s}$ given in Table 1, the PAFs for DC-SIGN binding to GNP-Man and GNP-DiMan were in the range of 0.18-1.8, and 13-131, respectively. While those for DC-SIGNR binding to GNP-(Man) 3 and GNP(DiMan) $)_{3}$ ranged from 0.011 to 0.11 , and 0.11 to 1.1 . Combining the PAF value and binding mode would allow us to predict the assembly outcome. For example, with a PAF of $>10$ and simultaneous binding, most of the added DC-SIGN molecules should readily bind to GNP-DiMan to saturate its surface binding capacity, giving rise to a rapidly increasing and quickly saturated $\mathrm{D}_{\mathrm{h}}$ with the increasing protein concentration. This was exactly what was measured from DLS. In contrast, the PAF of DC-SIGN-GNP-Man binding span across 1, which would indicate a gradually increased binding, again matching well to a positive, linear $\mathrm{D}_{\mathrm{h}}$-concentration relationship (Figure $4 \mathrm{~A}$ ). For inter-crosslinking binding between DC-SIGNR and GNPglycans, large-scale assemblies were only observed for GNP$(\text { DiMan })_{3}$ mixed with the highest protein concentration (200 $\mathrm{nM}$ ) which had a PAF of 1.1 and indicated the binding became favorable. While all other conditions where PAFs were $<1$, no significant binding (assembly) was observed (Figure 4B). Together, these results established PAF as a useful indicator for predicting the binding (assembly) outcome of multivalent lectin-glycan binding partners. Furthermore, the excellent agreement between the predicted outcome based on PAFs (derived from $\mathrm{K}_{\mathrm{d}} \mathrm{s}$ measured via the GNP quenching method) and those observed from DLS implied that this new fluorescence quenching based binding affinity method was highly credible and reliable. Interestingly, the ability of lectins to bind and inter-crosslink with virus surface glycoproteins had shown to play an important role in virus neutralization. ${ }^{64-66}$ Thus, we anticipate that the PAF criteria proposed here could act as a useful tool to predict lectin-virus interactions and neutralization.

Blocking DC-SIGN/R-mediated augmentation of Ebola virus glycoprotein-driven transduction. The distinct binding modes and affinities of GNP-glycans with two important viral receptors, DC-SIGN/R, should result in different abilities in blocking DC-SIGN/R-mediated virus infection of host cells. To investigate this potential and any possible correlation, human embryonic kidney 293 T cells transfected to express DC-SIGN or DC-SIGNR on their membrane were used as described previously. ${ }^{35}$ Murine leukemia virus (MLV) vector particles bearing the Ebola virus surface glycoprotein (EBOV-GP) and encoding the luciferase gene were used to model Ebola virus entry into cells. The virus particles can bind efficiently to DCSIGN/R (via their surface EBOV-GP) and binding results in increased transduction as determined by luciferase expression in host cells. ${ }^{34-35}$ Binding of high affinity GNP-glycans to host cell surface DC-SIGN/R could block these lectin receptors from further binding to EBOV-GP, reducing luciferase gene transduction. Indeed, pretreatment of $293 \mathrm{~T}$ cells with GNP-glycans ef- 
ficiently inhibited DC-SIGN-mediated augmentation of transduction in a dose-dependent manner (see SI, Figure S10). GNPDiMan/-(DiMan $)_{3}$ were found to be more potent in blocking the transduction than GNP-Man/-(Man) 3 . This result was consistent with the former being stronger DC-SIGN binders than the latter. The dose-dependent inhibition data were fitted well by a simple competition model:

$$
N A=I C_{50} /\left[I C_{50}+C\right]
$$

Where $N A, I C_{50}$ and $C$ were normalized luciferase activity, GNP concentration giving 50\% inhibition, and GNP concentration, respectively. Whilst DC-SIGNR-mediated augmentation of transduction was also inhibited by GNP-glycans, the resulting dose-dependent inhibition data were best fitted by a modified competition model:

$$
N A=E C_{50}{ }^{n} /\left[E C_{50}{ }^{n}+C^{\mathrm{n}}\right]
$$

Where the inhibition coefficient, $n$, was found to be in the range of 0.4 to 0.6 (Table 2). Moreover, GNP-glycans could not completely inhibit DC-SIGNR-mediated transduction, even at high concentrations (see Figure 5A/B, and also SI, Figure S11). This result revealed that GNP-glycans were much less effective in blocking DC-SIGNR-mediated augmentation of viral gene transduction as compared to that of DC-SIGN-dependent transduction.
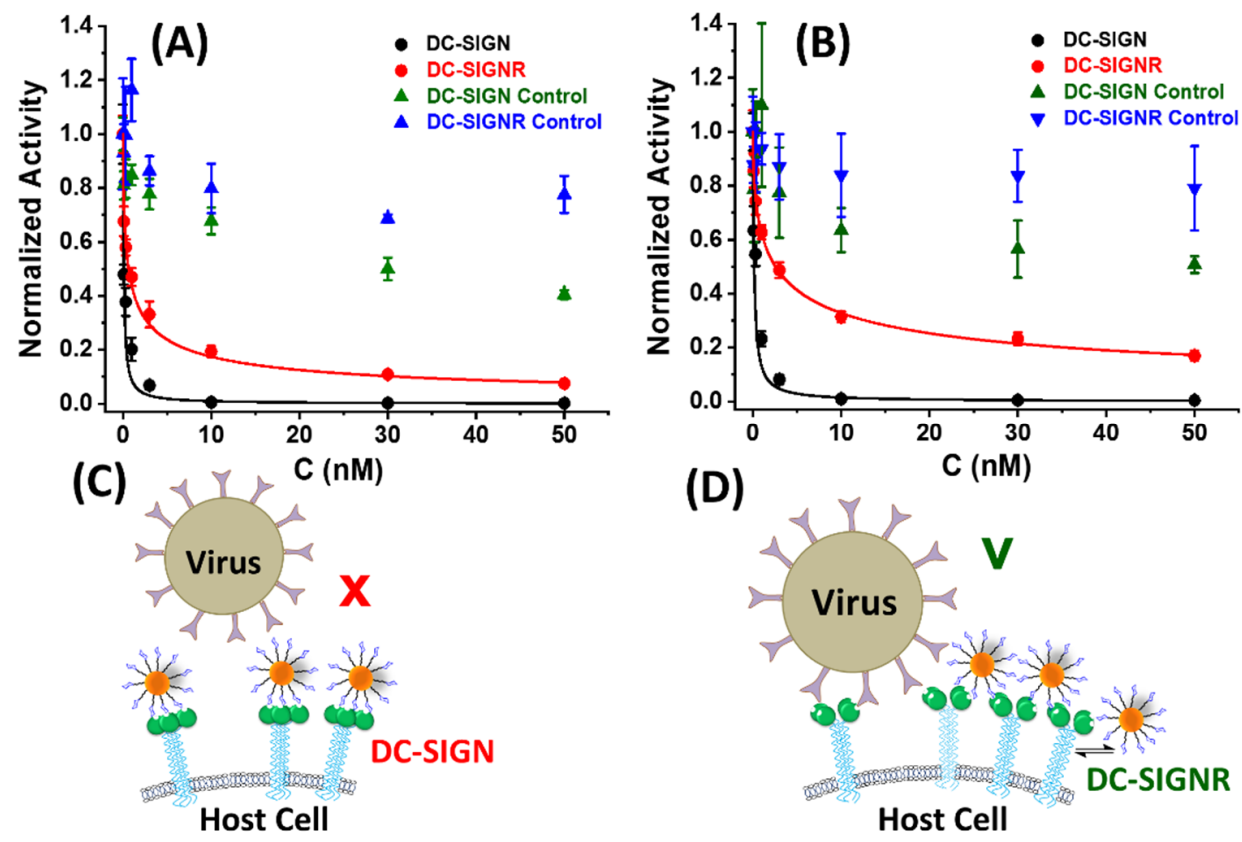

Figure 5. Plot of normalized luciferase activities of DC-SIGN- or DC-SIGNR- expressing 293T cells as a function of the concentration of GNP-DiMan (A) or GNP-(DiMan) 3 (B) inhibitors. Data for virus particles bearing the EBOV-GP are shown in dots while those of control virus particles bearing the VSV-G are shown in triangles. Schematics beneath showing the different inhibition efficiencies of GNP-glycans against DC-SIGN (C) or DC-SIGNR (D) mediated infections. (C) For DC-SIGN expressing host cells, all of the binding sites of its surface DC-SIGNs are bound and blocked by GNP-glycans, making them unavailable for further binding to virus surface EBOV-GPs to initiate infection. (D) For DC-SIGNR expressing host cells, GNP-glycans cross-link with some surface DC-SIGNRs but the bindings are weak and dynamic at the edges, allowing the virus to access the unblocked DC-SIGNR binding sites to initiate infection.

Table 2. Summary of inhibition data for GNP-glycans against DCSIGN/R-mediated EBOV-GP driven infection of $293 \mathrm{~T}$ host cells. * shows the $\mathrm{EC}_{50}$ values for DC-SIGNR.

\begin{tabular}{|l|l|l|c|c|}
\hline GNP-glycan & Receptor & $\begin{array}{l}\text { IC/EC } 50 \\
(\mathbf{n M})\end{array}$ & $\boldsymbol{n}$ & $\mathbf{R}^{\mathbf{2}}$ \\
\hline GNP-Man & DC-SIGN & $0.26 \pm 0.08$ & 1 & 0.889 \\
\hline GNP-(Man)3 & DC-SIGN & $1.57 \pm 0.25$ & 1 & 0.937 \\
\hline GNP-DiMan & DC-SIGN & $0.095 \pm 0.017$ & 1 & 0.921 \\
\hline GNP-(DiMan) 3 & DC-SIGN & $0.15 \pm 0.03$ & 1 & 0.890 \\
\hline GNP-Man & DC-SIGNR & $7.3 \pm 1.2^{*}$ & $0.42 \pm 0.04$ & 0.980 \\
\hline GNP-(Man)3 & DC-SIGNR & $53 \pm 17^{*}$ & $0.61 \pm 0.14$ & 0.902 \\
\hline GNP-DiMan & DC-SIGNR & $0.63 \pm 0.09^{*}$ & $0.56 \pm 0.02$ & 0.990 \\
\hline GNP-(DiMan) 3 & DC-SIGNR & $2.6 \pm 0.1^{*}$ & $0.53 \pm 0.02$ & 0.997 \\
\hline
\end{tabular}

We believe this result is reasonable from both the binding affinity (GNP-glycans bind more weakly to DC-SIGNR than to DC-
SIGN) and binding mode points of view. Each GNP-glycan could bind simultaneously to all 4 of DC-SIGN's binding sites, completely blocking them from further binding to virus surface EBOV-GPs to initiate cell entry (Figure 5C). In contrast, the inter-crosslinking mode of binding between GNP-glycans and DC-SIGNR meant that each GNP could only bind to 2 of the 4 binding sites in DC-SIGNR. It would be very difficult for GNPglycans to cross-link all cell surface DC-SIGNRs to fully block their binding sites. Even if this was possible, the DC-SIGNRs at the cluster edge would still only bind divalently (via 2 outward facing binding sites) to GNP-glycans, where the binding would be weak and dynamic. These, together with any unbound binding sites, could act as toe-holds for binding to viral surface EBOV-GPs to initiate cell uptake and infection (Figure 5D). Therefore, an inhibitor that inter-crosslinks with target receptors would be much less effective in blocking virus infection than its simultaneous binding counterpart, making it almost impossible to achieve complete inhibition (Figure 5C/D). Moreover, luciferase activities of control virus particles bearing the 
vesicular stomatitis virus glycoprotein (VSV-G), which cannot use DC-SIGN/R for augmentation of cell entry, were not affected significantly by GNP-glycan treatment, confirming that the observed inhibitory effects were specific (SI, Figure S10). Importantly, the $\mathrm{IC}_{50}$ value of GNP-DiMan in blocking DCSIGN-mediated augmentation of EBOV-GP-dependent entry was measured as $0.095 \pm 0.017 \mathrm{nM}$. This value was considerably lower (by almost an order of magnitude) than those measured for some of the most potent glycoconjugate inhibitors of Ebola virus infection reported previously (e.g. the giant globular multivalent glycofullerenes, $\mathrm{IC}_{50}: 0.67 \mathrm{nM}^{21}$, the virus-like glycodendrinanoparticles, $\mathrm{IC}_{50}: 0.91 \mathrm{nM},{ }^{16}$ and our previous QD$\mathrm{EG}_{3}$-DiMan, $\mathrm{IC}_{50}: 0.70 \pm 0.2 \mathrm{nM}^{35}$ ). This result demonstrated an outstanding potency of the GNP-glycans in blocking DCSIGN-mediated EBOV-GP driven infection of host cells. Importantly, as virus surface glycans are maintained by host cell's glycosylation apparatus, they are mostly conserved and unaffected by virus mutation. ${ }^{67}$ Therefore, the potential advantages of developing potent glycoconjugate viral inhibitors over other anti-viral strategies include two folds: (1) it can reduce the chances of virus mutation by blocking its entry to host cells, and (2) its treatment potency is unlikely affected by virus mutation, allowing us to provide a potentially long lasting solution.

\section{Conclusion}

In summary, we have developed polyvalent GNP-glycans as new powerful structural and mechanistic probes for multivalent lectin-glycan interactions. By exploiting GNPs' outstanding fluorescence quenching property, we have developed a new method for quantifying multivalent lectin-glycan interaction, revealing that a polyvalent display of mannose containing glycans on GNPs greatly enhances their binding affinities with two vitally important viral receptors, DC-SIGN/R. Moreover, by exploiting GNPs' nanoscale size and high TEM contrast, we have revealed the distinct binding mode and affinity enhancing mechanisms for GNP-glycans binding with DC-SIGN/R. Importantly, the assembly outcomes of the dose-dependent GNPlectin binding are in perfect agreement with those predicted from their respective binding modes and affinities, verifying the credibility of our new affinity method. Furthermore, we have found that GNP-glycans can potently block DC-SIGNmediated EBOV-GP driven viral infections of host cells with $\mathrm{IC}_{50}$ values down to $95 \pm 17 \mathrm{pM}$, making it the most potent glycoconjugate inhibitor against EBOV-GP driven infection. Notably, its inhibition potency will unlikely be affected by virus mutation, allowing us to provide potentially a long lasting solution. Finally, we have revealed that only a GNP-glycan inhibitor showing a simultaneous-, but not a crosslinking-, binding mode is able to completely block the target lectin mediated virus infection. Together, these data provide a useful guidance in designing polyvalent glycoconjugates for potent, specific inhibition of virus infection. Given their low-/non- toxicity and excellent biocompatibility, the GNP-glycans are perfectly placed for a wide range of applications, from probing fundamental structural mechanisms of glycobiology, developing novel biophysical and biomedical assays, to developing novel therapeutics against deadly virus infections and immune dysregulation diseases such as cancer, allergy and autoimmune diseases.

\section{Experimental Section}

Materials. Gold nanoparticle (nominal diameter $5 \mathrm{~nm}, \lambda_{\max } \sim 520$ $\mathrm{nm})$ was purchased from Sigma Aldrich as a stabilized suspension in citrate buffer or synthesized in house. 2-(2-aminoethoxy)-ethanol, Di-tert-butyl decarbonate, sodium sulfate, sodium hydride
(60\% dispersion in mineral oil), 3-bromo-1-propyne, potassium hydroxide, trifluoroacetic acid, triethylamine, sodium bicarbonate, $O$ (6-Chlorobenzotriazol-1-yl)- $N, N, N^{\prime}, N^{\prime}$-tetramethyluronium hexa fluorophosphate (HCTU), lipoic acid (LA), tris(2-carboxyethyl) phosphine hydrochloride (TCEP.HCl), copper sulfate, sodium ascorbate, Tris[(1-benzyl-1H-1,2,3-triazol-4-yl)methyl] amine (TBTA), tris(hydroxymethyl)aminomethane (Tris base), guanidine hydrochloride, anhydrous DMF and other chemicals were purchased from Sigma Aldrich, Alfa Aesar, Fluorochem, Thermo Scientific, VWR International or Acros organics with > 99\% impurity and used as received without further purification unless specified elsewhere. All the solvents were obtained in $>99 \%$ purity from Fischer Scientific and used as received. When used as reaction solvents in anhydrous reactions, THF and $\mathrm{CH}_{2} \mathrm{Cl}_{2}$ were dried and deoxygenated using an Innovative Technology Inc. PureSolv® solvent purification system. Ultra-pure water (resistance $>18.2$ $\mathrm{M} \Omega . \mathrm{cm}$ ) purified by an ELGA Purelab classic UVF system, was used for all experiments and making buffers..$^{59,62}$

Glycan-ligand synthesis by click chemistry. The general protocols employed in preparing the LA-glycan ligands via click chemistry were as follow. ${ }^{16}$ To a 1:1 (v:v) mixed THF: $\mathrm{H}_{2} \mathrm{O}$ solution (2.0$5.0 \mathrm{~mL}$ ) containing the glycan- $\mathrm{EG}_{2}-\mathrm{N}_{3}(1.1$ mole equiv.) and LAlinker ( 1 mole equiv.) were added $\mathrm{CuSO}_{4} .5 \mathrm{H}_{2} \mathrm{O}(0.036$ mole equiv.), TBTA ( 0.063 mole equiv.) followed by sodium ascorbate ( 0.135 mole equiv.) and the resulting solution was stirred at RT. After $3 \mathrm{~h}$, TLC confirmed the consumption of all starting materials. The solvent was then evaporated and the crude product was purified by size exclusion chromatography using Biogel P2 column using water as eluent to afford the desired pure LA-glycan product.

LA-Man: Yield $=(67 \%, 0.18 \mathrm{mmol}) .{ }^{1} \mathrm{H}$ NMR $\left(500 \mathrm{MHz}, \mathrm{CD}_{3} \mathrm{OD}\right)$ $\delta(\mathrm{ppm}): 8.04$ (s, $1 \mathrm{H}$, triazole-H), $4.8(\mathrm{~d}, 1 \mathrm{H}, J 1.6 \mathrm{~Hz}$, Man H-1), $4.65(\mathrm{~s}, 2 \mathrm{H}), 4.6(\mathrm{t}, 2 \mathrm{H}, J 5 \mathrm{~Hz}), 3.9(\mathrm{t}, 2 \mathrm{H}, J 5.1 \mathrm{~Hz}), 3.86-3.81(\mathrm{~m}$, $3 \mathrm{H}), 3.8(\mathrm{dd}, 1 \mathrm{H}, J 1.7 \mathrm{~Hz}, 3.4 \mathrm{~Hz}, \mathrm{Man} \mathrm{H}-2), 3.72(\mathrm{~d}, 1 \mathrm{H}, J 5.5$ $\mathrm{Hz}), 3.69-3.67(\mathrm{~m}, 3 \mathrm{H}), 3.66(\mathrm{~s}, 2 \mathrm{H}), 3.65-3.63(\mathrm{~m}, 2 \mathrm{H}), 3.62-3.61$ (m, 4H), 3.60-3.57 (m, 2H), 3.53 (t, 2H, J 5.5 Hz), 3.39-3.34 (m, $3 \mathrm{H}), 3.20-3.15(\mathrm{~m}, 1 \mathrm{H}), 3.12-3.07(\mathrm{~m}, 1 \mathrm{H}), 2.49-2.42(\mathrm{~m}, 1 \mathrm{H}), 2.20$ (t, $2 \mathrm{H}, J 7.4 \mathrm{~Hz}), 1.92-1.85(\mathrm{~m}, 1 \mathrm{H}), 1.73-1.59(\mathrm{~m}, 4 \mathrm{H}), 1.50-1.40$ $(\mathrm{m}, 2 \mathrm{H}) .{ }^{13} \mathrm{C}$ NMR $\left(125 \mathrm{MHz}, \mathrm{CD}_{3} \mathrm{OD}\right) \delta: 176.1(\mathrm{C}=\mathrm{O}), 145.7$ $(\underline{\mathrm{C}}=\mathrm{CH}), 126.0(\mathrm{C}=\underline{\mathrm{C}} \mathrm{H}), 101.7(\mathrm{Man} \mathrm{C}-1), 74.6,72.6,72.1$ (Man C-2), 71.6, 71.5, 71.4, 71.3, 70.8, 70.6, 70.4, 68.6, 67.7, 65.0, 63.0 (Man C-6), 57.6, 51.5, 41.3, 40.3, 39.3, 36.8, 35.7, 29.8, 26.7. HRMS: calculated $\mathrm{m} / z$ for $\mathrm{C}_{27} \mathrm{H}_{49} \mathrm{~N}_{4} \mathrm{O}_{11} \mathrm{~S}_{2}(\mathrm{M}+\mathrm{H})^{+} 669.2834$; found 669.2838 .

LA-DiMan: Yield $=(65 \%, 0.080 \mathrm{mmol}) .{ }^{1} \mathrm{H}$ NMR $(500 \mathrm{MHz}$, $\left.\mathrm{CD}_{3} \mathrm{OD}\right) \delta(\mathrm{ppm}): 8.05(\mathrm{~s}, 1 \mathrm{H}$, triazole-H), $5.11(\mathrm{~d}, J 1.7 \mathrm{~Hz}, 1 \mathrm{H})$, $4.96(\mathrm{~d}, J 1.8 \mathrm{~Hz}, 1 \mathrm{H}), 4.66(\mathrm{~s}, 2 \mathrm{H}), 4.60(\mathrm{t}, 2 \mathrm{H}, J 5.1 \mathrm{~Hz}), 3.97(\mathrm{dd}$, $1 \mathrm{H}, J 3.3,1.8 \mathrm{~Hz}), 3.91(\mathrm{dd}, 2 \mathrm{H}, J 5.5,4.7 \mathrm{~Hz}), 3.88-3.78(\mathrm{~m}, 6 \mathrm{H})$, $3.72-3.65(\mathrm{~m}, 8 \mathrm{H}), 3.62(\mathrm{dt}, 6 \mathrm{H}, J 5.0,1.3 \mathrm{~Hz}), 3.58(\mathrm{dt}, 3 \mathrm{H}, J$ $11.2,1.6 \mathrm{~Hz}), 3.53(\mathrm{t}, 2 \mathrm{H}, J 5.5 \mathrm{~Hz}), 3.43-3.32(\mathrm{~m}, 3 \mathrm{H}), 3.17$ (ddd, $1 \mathrm{H}, J 10.9,7.1,5.4 \mathrm{~Hz}), 3.10(\mathrm{dt}, 1 \mathrm{H}, J 11.0,6.9 \mathrm{~Hz}, 1 \mathrm{H}), 2.46(\mathrm{dtd}$, $1 \mathrm{H}, J 12.1,6.7,5.4 \mathrm{~Hz}), 2.20(\mathrm{t}, 2 \mathrm{H}, J 7.4 \mathrm{~Hz}), 1.89(\mathrm{dq}, 1 \mathrm{H}, J 12.7$, $6.9 \mathrm{~Hz}), 1.77-1.57(\mathrm{~m}, 4 \mathrm{H}), 1.45(\mathrm{qt}, 2 \mathrm{H}, J 9.4,5.9 \mathrm{~Hz}) .{ }^{13} \mathrm{C}$ NMR $\left(125 \mathrm{MHz}, \mathrm{CD}_{3} \mathrm{OD}\right) \delta$ : $176.1(\mathrm{C}=\mathrm{O}), 145.7(\underline{\mathrm{C}}=\mathrm{CH}), 126.0$ $(\mathrm{C}=\underline{\mathrm{CH}}$ ), 104.2 (Man C-1), 100.1 (Man C-1'), 80.6, 75.1, 74.7, 72.4, 72.1, 71.9, 71.6, 71.5, 71.4, 71.3, 70.8, 70.6, 70.5, 69.0, 68.8, 67.9, 65.0, 63.2, 63.1, 57.6, 51.5, 41.3, 40.4, 39.3, 36.8, 35.7, 29.8, 26.7. HRMS: calculated $m / z$ for $\mathrm{C}_{33} \mathrm{H}_{58} \mathrm{~N}_{4} \mathrm{O}_{16} \mathrm{~S}_{2}(\mathrm{M}+\mathrm{H})^{+} 831.3233$; found 831.3242 .

LA-(Man) $)_{3}$ : Yield $=(60 \%, 0.060 \mathrm{mmol}) .{ }^{1} \mathrm{H}$ NMR $\left(500 \mathrm{MHz}, \mathrm{D}_{2} \mathrm{O}\right)$ $\delta$ (ppm): 8.03 (s, 3H, triazole-H), $4.87(\mathrm{~d}, 3 \mathrm{H}, J 1.8 \mathrm{~Hz}, \mathrm{H}-1), 4.64$ $-4.61(\mathrm{~m}, 6 \mathrm{H}), 4.60(\mathrm{~s}, 6 \mathrm{H}), 3.98-3.96(\mathrm{~m}, 6 \mathrm{H}), 3.95(\mathrm{dd}, 3 \mathrm{H}, J$ $3.5,1.8 \mathrm{~Hz}, \mathrm{H}-2), 3.89(\mathrm{~d}, 1 \mathrm{H}, J 2.0 \mathrm{~Hz}), 3.87(\mathrm{~d}, 2 \mathrm{H}, J 1.7 \mathrm{~Hz})$, $3.84-3.79(\mathrm{~m}, 6 \mathrm{H}), 3.77(\mathrm{~d}, 2 \mathrm{H}, J 5.6 \mathrm{~Hz}), 3.74(\mathrm{~d}, 7 \mathrm{H}, J 3.1 \mathrm{~Hz})$, $3.67(\mathrm{~d}, 3 \mathrm{H}, J 9.8 \mathrm{~Hz}), 3.65-3.61(\mathrm{~m}, 25 \mathrm{H}), 3.61-3.53(\mathrm{~m}, 3 \mathrm{H})$, $3.21-3.12(\mathrm{~m}, 2 \mathrm{H}), 2.42(\mathrm{dq}, 1 \mathrm{H}, J 12.3,6.1 \mathrm{~Hz}), 2.18(\mathrm{t}, 2 \mathrm{H}, J$ 
$7.0 \mathrm{~Hz}), 1.91(\mathrm{dt}, 1 \mathrm{H}, J 13.6,6.8 \mathrm{~Hz}), 1.71-1.64(\mathrm{~m}, 1 \mathrm{H}), 1.58-$ $1.48(\mathrm{~m}, 4 \mathrm{H}), 1.33(\mathrm{q}, 3 \mathrm{H}, J 7.7 \mathrm{~Hz}) .{ }^{13} \mathrm{C}$ NMR $\left(125 \mathrm{MHz}, \mathrm{D}_{2} \mathrm{O}\right) \delta$ : $176.5(\mathrm{C}=\mathrm{O}), 144.0,125.3,99.9(\mathrm{C}-1), 72.7,70.5,69.9,69.5,69.4$, $68.8,67.5,66.7,66.3,63.5,60.9,59.7,56.5,50.0,40.2,38.0,35.9$, 33.7, 27.5, 24.9. HRMS: calculated $m / z$ for $\mathrm{C}_{57} \mathrm{H}_{99} \mathrm{~N}_{10} \mathrm{O}_{28} \mathrm{~S}_{2}$ $(\mathrm{M}+\mathrm{H})^{+}$1435.6066; found 1435.6096.

LA-(DiMan) $)_{3}$ : Yield $=(69 \%, 0.030 \mathrm{mmol}) .{ }^{1} \mathrm{H}$ NMR $(500 \mathrm{MHz}$, $\left.\mathrm{D}_{2} \mathrm{O}\right) \delta(\mathrm{ppm}): 8.03(\mathrm{~s}, 3 \mathrm{H}$, triazole- $\mathrm{H}), 5.11(\mathrm{~d}, 3 \mathrm{H}, J 1.8 \mathrm{~Hz}, \mathrm{H}-1)$, $5.03\left(\mathrm{~d}, 3 \mathrm{H}, J=1.9 \mathrm{~Hz}, \mathrm{H}-1^{\prime}\right), 4.64-4.62(\mathrm{~m}, 6 \mathrm{H}), 4.60(\mathrm{~d}, 6 \mathrm{H}, J$ $2.9 \mathrm{~Hz}$ ), 4.08 (dd, 3H, J 3.4, $1.8 \mathrm{~Hz}, \mathrm{H}-2$ ), 3.97 (td, 9H, $J=4.5,2.5$ $\mathrm{Hz}), 3.92-3.68(\mathrm{~m}, 40 \mathrm{H}), 3.66-3.61(\mathrm{~m}, 29 \mathrm{H}), 3.58-3.53(\mathrm{~m}$, $3 \mathrm{H}), 3.21-3.13(\mathrm{~m}, 2 \mathrm{H}), 2.42(\mathrm{dq}, 1 \mathrm{H}, J 12.3,6.1 \mathrm{~Hz}), 2.18(\mathrm{t}, 2 \mathrm{H}$, $J 7.0 \mathrm{~Hz}), 1.91(\mathrm{dd}, 1 \mathrm{H}, J 13.1,6.8 \mathrm{~Hz}), 1.67(\mathrm{~m}, 1 \mathrm{H}), 1.59-1.49$ (m, 4H), 1.32 (p, 3H, J 7.7 Hz). ). ${ }^{13} \mathrm{C}$ NMR $\left(125 \mathrm{MHz}, \mathrm{D}_{2} \mathrm{O}\right) \delta$ : $179.0(\mathrm{C}=\mathrm{O}), 146.5,127.9,104.8(\mathrm{C}-1), 100.9(\mathrm{C}-2), 81.2,75.8$, 75.3, 74.2, 72.8, 72.7, 72.5, 72.2, 72.0 (2), 71.9, 71.3 (2), 70.1, 69.4 (2), 69.0, 66.1, 63.7, 63.4, 62.9, 62.3, 59.0, 52.6, 42.8, 40.6, 38.4, 36.2 , 30.1, 27.4. HRMS: calculated $m / z$ for $\mathrm{C}_{75} \mathrm{H}_{130} \mathrm{~N}_{10} \mathrm{O}_{43} \mathrm{~S}_{2}$ $(\mathrm{M}+\mathrm{H})^{2+}$ 961.3862; found 961.3858.

GNP-glycan preparation. $10 \mathrm{~mL}$ of $5 \mathrm{~nm}$ GNP stock was concentrated to $250 \mu \mathrm{L}$ using a $30 \mathrm{KDa}$ MWCO spin column and washed with $\mathrm{H}_{2} \mathrm{O}(3 \times 200 \mu \mathrm{L})$ to remove any impurities. Then DHLAglycan ligands dissolved in $\mathrm{H}_{2} \mathrm{O}$ were added to the GNP solution in a molar ratio of GNP:DHLA-glycan $=1: 1000$. The resulting solution was mixed and stirred at RT in dark for overnight. The resulting mixture was passed through a $30 \mathrm{KDa}$ MWCO spin column by centrifugation at $15,000 \times \mathrm{g}$ for $2 \mathrm{~min}$ and the residues were washed with $\mathrm{H}_{2} \mathrm{O}(3 \times 200 \mu \mathrm{L})$ to give the GNP-glycan stock. The filtrate and washing through liquids were combined and used to evaluate the glycan loading on GNPs as described previously. ${ }^{34}$ The concentration of the GNP-glycans was determined from its absorbance at $520 \mathrm{~nm}$ using the Beer-Lambert law and a GNP molar extinction co-efficient of $1.1 \times 10^{7} \mathrm{M}^{-1} \cdot \mathrm{cm}^{-1}$.

Protein production and labeling. The soluble extracellular segments of DCSIGN (DC020) and DCSIGNR (DSR034) were expressed as inclusion bodies in E. coli and purified by Man-Sepharose affinity column followed by Superdex size exclusion column as reported previously. ${ }^{34}$ The mutant proteins, DC020 Q-274C and DSR034 R278C were constructed by site directed mutagenesis and labelled with atto594-maleimide as described previously. ${ }^{35,40}$ The labeled proteins were purified by mannose-Sepharose affinity column. All the proteins obtained were characterized by high resolution mass spectroscopy (HRMS) and their corresponding spectra were shown in SI, Figure S1. The dye labeling efficiency (per protein monomer) for DC-SIGN and DC-SIGNR was determined to be $87 \%$ and $82 \%$, respectively, based on the relative intensity of the labeled and unlabeled protein peaks measured from MS.

Fluorescence spectra. All fluorescence spectra were recorded on a Cary Eclipse Fluorescence Spectrophotometer using a $0.70 \mathrm{~mL}$ quartz cuvette under a fixed $\lambda_{\mathrm{EX}}$ of $595 \mathrm{~nm}$ over a range of 605-750 $\mathrm{nm}$. All measurements were performed in a binding buffer $(20 \mathrm{mM}$ HEPES, $100 \mathrm{mM} \mathrm{NaCl}, 10 \mathrm{mM} \mathrm{CaCl}_{2}, \mathrm{pH}$ 7.8) containing $1 \mathrm{mg} / \mathrm{mL}$ of BSA to minimize any nonspecific absorption of the GNPs and proteins on surfaces. For apparent $\mathrm{K}_{d}$ measurement, the concentrations of labeled DC-SIGN or DC-SIGNR protein and GNP-glycans were varied simultaneously in a fixed protein:GNP molar ratio of 1:1. The samples were incubated at RT for $20 \mathrm{~min}$ before recording the fluorescence spectra. The fluorescence spectra of the protein in the absence of the GNP-glycans, recorded under identical experiment conditions, were used to determine the quenching efficiency. The instrument PMT voltages were adjusted to compensate the low fluorescence signals at low concentrations. The quenching efficiency (QE) of DC-SIGN/R binding to each GNP-glycan was calculated via Eq. 1 and the resulting QE-concentration relationship was fitted by Hill's equation (Eq. 2) to derive the apparent binding $\mathrm{K}_{\mathrm{d}}$ values.

Dynamic light scattering. The hydrodynamic diameters $\left(D_{h}\right)$ of wildtype DC-SIGN/R and GNP-glycans in pure water and in a binding buffer (20 mM HEPES, $100 \mathrm{mM} \mathrm{NaCl}, 10 \mathrm{mM} \mathrm{CaCl}_{2}, \mathrm{pH}$ 7.8) were recorded on a Malvern ZETASizer-Nano using disposable polystyrene cuvettes as reported in our previous papers. ${ }^{35,68}$ For monitoring GNP-DiMan binding to wildtype DC-SIGN/R, a series of samples, each containing GNP-DiMan $(10 \mathrm{nM})$ and a varying amount of wildtype DC-SIGN/R, were mixed in a binding buffer at RT for 20 mins before DLS measurement was carried out. 10 consecutive scans were performed for each sample and the resulting volume $\mathrm{D}_{\mathrm{h}}$ distribution histograms for each sample were combined and fitted by Gaussian distributions to estimate their $D_{h} s^{35}$

TEM imaging. Three samples: (1) GNP-DiMan, (2) GNP-DiMan + wildtype DC-SIGN, and (3) GNP-DiMan + wildtype DC-SIGNR were incubated (final $\mathrm{C}_{\mathrm{GNP}}=16 \mathrm{nM}$ and $\mathrm{C}_{\text {protein }}=640 \mathrm{nM}$ ) in a binding buffer overnight. The samples were prepared by plunge-freezing into liquid ethane followed by warming under vacuum to capture the GNP dispersions in their native dispersed state as demonstrated in our previous paper. ${ }^{63}$ Briefly, $3.5 \mu \mathrm{L}$ of suspension was placed onto a plasma-cleaned TEM grid with a continuous carbon support film, blotted, and plunge frozen into liquid ethane. The TEM grids were then warmed to RT over several minutes by placing the specimens in the liquid nitrogen cooled storage container in a rotary pumped vacuum desiccator.

The samples were then analyzed using an FEI Titan ${ }^{3}$ Themis 300 G2 S/TEM equipped with FEI SuperX energy dispersive X-ray (EDX) spectrometers and a Gatan OneView CCD. Images were collected for each sample, with EDX spectroscopy used to confirm that the small nanoparticles imaged were indeed GNPs as Au species were detected together with other peaks (carbon, oxygen, silicon, and copper) due to the microscope, TEM grid or support film. A series of images at the same magnification were recorded for each sample, allowing easy comparison of the nanoparticle dispersion state of the three samples. The TEM images were analyzed automatically by MATLAB scripts to derive the nearest neighbor distances (NNDs) as reported previously. ${ }^{35}$

Virus Inhibition. The effects of GNP-glycans (glycan = Man, DiMan, (Man) 3 or (DiMan) 3 ) on Ebola virus glyco-protein (EBOVGP) driven entry into $293 \mathrm{~T}$ cells were assessed by using our established procedures. ${ }^{34-35}$ Briefly, 293T cells seeded in 96-well plates were transfected with plasmids encoding DC-SIGN or DC-SIGNR or control transfected with empty plasmid (pcDNA). The cells were washed at $16 \mathrm{~h}$ post transfection and further cultivated at $37^{\circ} \mathrm{C}, 5 \%$ $\mathrm{CO}_{2}$ in Dulbecco's modified eagle medium (DMEM) containing $10 \%$ fetal bovine serum (FBS). At $48 \mathrm{~h}$ post transfection, the cells were exposed to twice the final concentration of GNP-glycan inhibitor in DMEM supplemented with $10 \%$ FBS for 30 min in a total volume of $50 \mu \mathrm{L}$. Thereafter, the resulting cells were inoculated with $50 \mu \mathrm{L}$ of preparations of MLV vector particles encoding the luciferase gene and bearing either EBOV-GP (which can use DCSIGN/R for augmentation of host cell entry) or the vesicular stomatitis virus glycoprotein (VSV-G, which cannot use DC-SIGN/R for augmentation of host cell entry). Under these conditions, binding of GNP-glycan nanoparticles to 293T cell surface DC-SIGN/R receptors can block EBOV-GP interactions with these lectin receptors, resulting in reduced transduction efficiency of the virus particles and hence reducing the cellular luciferase activity. At $6 \mathrm{~h}$ post inoculation, $100 \mu \mathrm{L}$ of fresh DMEM culture medium was added and the cells incubated for another $72 \mathrm{~h}$. Thereafter, luciferase activities in cell lysates were determined using a commercially available kit (PJK), following the manufacturer's instructions, as described in our previous publication. 


\section{ASSOCIATED CONTENT}

Supporting Information. Experimental details including materials and methods, protein production, labeling and MS characterization, LA-glycan ligands syntheses and their ${ }^{1} \mathrm{H}$ and ${ }^{13} \mathrm{C}$ NMR spectra, and supporting figures showing fluorescence spectra of GNPDiMan binding to DC-SIGN, mannose competition studies, $\mathrm{D}_{\mathrm{h}}$ distribution histograms of the GNP-glycans, DC-SIGN/R, and GNPglycan binding to DC-SIGN/R at different concentrations, TEM images of cryo-prepared GNP-DiMan + DC-SIGN/R samples, and the original data of GNP-glycans inhibiting DC-SIGN/R-mediated EBOV-GP driven infections.

\section{AUTHOR INFORMATION}

\section{Corresponding Author(s)}

* Stefan Pöhlmann- Infection Biology Unit, German Primate Center, Kellnerweg 4, 37077 Gottingen, Germany; orcid.org/00000001-6086-9136; Email: spoehlmann@ @ dpz.eu.

* Yuan Guo- School of Food Science\&Nutrition and Astbury Center for Structural Molecular Biology, University of Leeds, UK; orcid.org/0000-0003-4607-7356; Email: y.guo@leeds.ac.uk .

* Dejian Zhou- School of Chemistry and Astbury Center for Structural Molecular Biology, University of Leeds, UK; orcid.org/ 00000003-3314-9242; Email: d.zhou@leeds.ac.uk.

\section{Author Contributions}

D.Z., Y.G. and S.P. conceived the idea. D.B. and E.P. conducted ligand synthesis, GNP conjugation and GNP-lectin binding studies. I.N. conducted virus inhibition assays; D.B., Y.L. and B.W.T. synthesized glycans; J.H. and E.K. performed some protein purification, characterization and DLS studies. U.S.A. provided some GNPs. N.H. performed TEM imaging studies. D.Z., Y.G. and D. B. analyzed data and wrote the paper. All authors have given approval to the final version of the manuscript.

艺These authors contributed equally to this work.

\section{Funding Sources}

UK Biotechnology and Biological Sciences Research Council (grant no: BB/R007829/1). EU Horizon 2020 Marie SklodowskaCurie Fellowship (grant no: 797597). UK Engineering and Physical Sciences Research Council DTP PhD scholarship (grant no: EP/M50807X/1).

\section{Notes}

The authors declare no competing financial interests.

\section{ACKNOWLEDGMENT}

We thank the UK Biotechnology and Biological Sciences Research Council (grant no: BB/R007829/1) and the EU Horizon 2020 via a Marie Sklodowska-Curie Fellowship (grant no: 797597) for funding this research. E.P. thanks the University of Leeds and the UK Engineering and Physical Sciences Research Council for providing a DTP PhD scholarship (grant no: EP/M50807X/1).

\section{ABBREVIATIONS}

GNP, gold nanoparticle; DC-SIGN, Dendritic Cell-Specific Intercellular adhesion molecule-3-Grabbing Non-integrin; DC-SIGNR, DC-SIGN related lectin found on endothelial cells; TLC, thin layer chromatography; HPLC: high performance liquid chromatography; NMR, nuclear magnetic resonance; MS, mass spectrometry.

\section{REFERENCES}

1. Brown, G. D.; Willment, J. A.; Whitehead, L., C-type lectins in immunity and homeostasis. Nat. Rev. Immunol. 2018, 18 (6), 374389.

2. Cummings, R. D., "Stuck on sugars - how carbohydrates regulate cell adhesion, recognition, and signaling". Glycoconj. J. 2019, 36 (4), 241-257.

3. Geijtenbeek, T. B.; Gringhuis, S. I., Signalling through Ctype lectin receptors: shaping immune responses. Nat. Rev. Immunol. 2009, 9 (7), 465-79.

4. Macauley, M. S.; Crocker, P. R.; Paulson, J. C., Siglec-mediated regulation of immune cell function in disease. Nat. Rev. Immunol. 2014, 14 (10), 653-666.

5. Rabinovich, G. A.; van Kooyk, Y.; Cobb, B. A., Glycobiology of immune responses. Ann. N. Y. Acad. Sci. 2012, 1253, 1-15.

6. Taylor, M. E.; Drickamer, K., Paradigms for glycan-binding receptors in cell adhesion. Curr. Opin. Cell. Biol. 2007, 19 (5), 572577.

7. Thompson, A. J.; de Vries, R. P.; Paulson, J. C., Virus recognition of glycan receptors. Curr. Opin. Virol. 2019, 34, 117-129.

8. Wesener, D. A.; Dugan, A.; Kiessling, L. L., Recognition of microbial glycans by soluble human lectins. Curr. Opin. Struct. Biol. 2017, 44, 168-178.

9. Illescas, B. M.; Rojo, J.; Delgado, R.; Martin, N., Multivalent Glycosylated Nanostructures To Inhibit Ebola Virus Infection. J. Am. Chem. Soc. 2017, 139 (17), 6018-6025.

10. Mammen, M.; Choi, S. K.; Whitesides, G. M., Polyvalent Interactions in Biological Systems: Implications for Design and Use of Multivalent Ligands and Inhibitors. Angew. Chem. Int. Ed. 1998, 37 (20), 2754-2794.

11. Kitov, P. I.; Sadowska, J. M.; Mulvey, G.; Armstrong, G. D.; Ling, H.; Pannu, N. S.; Read, R. J.; Bundle, D. R., Shiga-like toxins are neutralized by tailored multivalent carbohydrate ligands. Nature $\mathbf{2 0 0 0}$, 403 (6770), 669-672.

12. Dam, T. K.; Brewer, C. F., Multivalent lectin-carbohydrate interactions energetics and mechanisms of binding. Adv. Carbohydr. Chem. Biochem. 2010, 63, 139-164.

13. Branson, T. R.; McAllister, T. E.; Garcia-Hartjes, J.; Fascione, M. A.; Ross, J. F.; Warriner, S. L.; Wennekes, T.; Zuilhof, H.; Turnbull, W. B., A protein-based pentavalent inhibitor of the cholera toxin B-subunit. Angew. Chem. Int. Ed. 2014, 53 (32), 8323-8327.

14. Bernardi, A.; Jimenez-Barbero, J.; Casnati, A.; De Castro, C.; Darbre, T.; Fieschi, F.; Finne, J.; Funken, H.; Jaeger, K. E.; Lahmann, M.; Lindhorst, T. K.; Marradi, M.; Messner, P.; Molinaro, A.; Murphy, P. V.; Nativi, C.; Oscarson, S.; Penades, S.; Peri, F.; Pieters, R. J.; Renaudet, O.; Reymond, J. L.; Richichi, B.; Rojo, J.; Sansone, F.; Schaffer, C.; Turnbull, W. B.; Velasco-Torrijos, T.; Vidal, S.; Vincent, S.; Wennekes, T.; Zuilhof, H.; Imberty, A., Multivalent glycoconjugates as anti-pathogenic agents. Chem. Soc. Rev. 2013, 42 (11), 47094927.

15. Feinberg, H.; Castelli, R.; Drickamer, K.; Seeberger, P. H.; Weis, W. I., Multiple modes of binding enhance the affinity of DCSIGN for high mannose N-linked glycans found on viral glycoproteins. J. Biol. Chem. 2007, 282 (6), 4202-4209.

16. Ribeiro-Viana, R.; Sanchez-Navarro, M.; Luczkowiak, J.; Koeppe, J. R.; Delgado, R.; Rojo, J.; Davis, B. G., Virus-like glycodendrinanoparticles displaying quasi-equivalent nested polyvalency upon glycoprotein platforms potently block viral infection. Nat. Commun. 2012, 3, article no: 1303 .

17. Martinez, A.; Ortiz Mellet, C.; Garcia Fernandez, J. M., Cyclodextrin-based multivalent glycodisplays: covalent and supramolecular conjugates to assess carbohydrate-protein interactions. Chem. Soc. Rev. 2013, 42 (11), 4746-4773.

18. Reichardt, N. C.; Martin-Lomas, M.; Penades, S., Glyconanotechnology. Chem. Soc. Rev. 2013, 42 (10), 4358-4376.

19. Spinelli, N.; Defrancq, E.; Morvan, F., Glycoclusters on oligonucleotide and PNA scaffolds: synthesis and applications. Chem. Soc. Rev. 2013, 42 (11), 4557-4573.

20. Muller, C.; Despras, G.; Lindhorst, T. K., Organizing multivalency in carbohydrate recognition. Chem. Soc. Rev. 2016, 45 (11), 3275-3302. 
21. Munoz, A.; Sigwalt, D.; Illescas, B. M.; Luczkowiak, J.; Rodriguez-Perez, L.; Nierengarten, I.; Holler, M.; Remy, J. S.; Buffet, K.; Vincent, S. P.; Rojo, J.; Delgado, R.; Nierengarten, J. F.; Martin, N., Synthesis of giant globular multivalent glycofullerenes as potent inhibitors in a model of Ebola virus infection. Nat. Chem. 2016, 8 (1), 5057.

22. Martinez-Avila, O.; Hijazi, K.; Marradi, M.; Clavel, C.; Campion, C.; Kelly, C.; Penades, S., Gold manno-glyconanoparticles: multivalent systems to block HIV-1 gp120 binding to the lectin DCSIGN. Chem. Eur. J. 2009, 15 (38), 9874-9888.

23. Benito-Alifonso, D.; Tremel, S.; Hou, B.; Lockyear, H.; Mantell, J.; Fermin, D. J.; Verkade, P.; Berry, M.; Galan, M. C., Lactose as a "Trojan horse" for quantum dot cell transport. Angew. Chem. Int. Ed. 2014, 53 (3), 810-814.

24. Bhatia, S.; Camacho, L. C.; Haag, R., Pathogen Inhibition by Multivalent Ligand Architectures. J. Am. Chem. Soc. 2016, 138 (28), 8654-8666.

25. Holla, A.; Skerra, A., Comparative analysis reveals selective recognition of glycans by the dendritic cell receptors DC-SIGN and Langerin. Protein Eng. Des. Sel. 2011, 24 (9), 659-669.

26. Diehl, C.; Engstrom, O.; Delaine, T.; Hakansson, M.; Genheden, S.; Modig, K.; Leffler, H.; Ryde, U.; Nilsson, U. J.; Akke, M., Protein flexibility and conformational entropy in ligand design targeting the carbohydrate recognition domain of galectin-3. J. Am. Chem. Soc. 2010, 132 (41), 14577-14589.

27. Turnbull, W. B.; Precious, B. L.; Homans, S. W., Dissecting the cholera toxin-ganglioside GM1 interaction by isothermal titration calorimetry. J. Am. Chem. Soc. 2004, 126 (4), 1047-1054.

28. Giljohann, D. A.; Seferos, D. S.; Daniel, W. L.; Massich, M. D.; Patel, P. C.; Mirkin, C. A., Gold nanoparticles for biology and medicine. Angew. Chem. Int. Ed. 2010, 49 (19), 3280-3294.

29. Rosi, N. L.; Mirkin, C. A., Nanostructures in biodiagnostics. Chem. Rev. 2005, 105 (4), 1547-1562.

30. Schofield, C. L.; Field, R. A.; Russell, D. A., Glyconanoparticles for the colorimetric detection of cholera toxin. Anal. Chem. 2007, 79 (4), 1356-1361.

31. Fang, S. P.; Lee, H. J.; Wark, A. W.; Corn, R. M., Attomole microarray detection of MicroRNAs by nanoparticle-amplified SPR imaging measurements of surface polyadenylation reactions. J. Am. Chem. Soc. 2006, 128 (43), 14044-14046.

32. Graham, D.; Thompson, D. G.; Smith, W. E.; Faulds, K., Control of enhanced Raman scattering using a DNA-based assembly process of dye-coded nanoparticles. Nat. Nanotech. 2008, 3 (9), 548551

33. Cao, Y. W. C.; Jin, R. C.; Mirkin, C. A., Nanoparticles with Raman spectroscopic fingerprints for DNA and RNA detection. Science 2002, 297 (5586), 1536-1540.

34. Guo, Y.; Sakonsinsiri, C.; Nehlmeier, I.; Fascione, M. A.; Zhang, H.; Wang, W.; Pohlmann, S.; Turnbull, W. B.; Zhou, D., Compact, Polyvalent Mannose Quantum Dots as Sensitive, Ratiometric FRET Probes for Multivalent Protein-Ligand Interactions. Angew. Chem. Int. Ed. 2016, 55 (15), 4738-4742.

35. Guo, Y.; Nehlmeier, I.; Poole, E.; Sakonsinsiri, C.; Hondow, N.; Brown, A.; Li, Q.; Li, S.; Whitworth, J.; Li, Z.; Yu, A.; Brydson, R.; Turnbull, W. B.; Pohlmann, S.; Zhou, D., Dissecting Multivalent Lectin-Carbohydrate Recognition Using Polyvalent Multifunctional Glycan-Quantum Dots. J. Am. Chem. Soc. 2017, 139 (34), 1183311844.

36. Hooper, J. G., Y.; Zhou, D., , Polyvalent Glycan-Quantum Dots as Multifunctional Structural Probes for Multivalent Lectin-Carbohydrate Interactions. ACS Symp. Series 2020, 1346, 47-66.

37. Geijtenbeek, T. B.; Kwon, D. S.; Torensma, R.; van Vliet, S. J.; van Duijnhoven, G. C.; Middel, J.; Cornelissen, I. L.; Nottet, H. S.; KewalRamani, V. N.; Littman, D. R.; Figdor, C. G.; van Kooyk, Y., DC-SIGN, a dendritic cell-specific HIV-1-binding protein that enhances trans-infection of T cells. Cell 2000, 100 (5), 587-597.

38. Guo, Y.; Feinberg, H.; Conroy, E.; Mitchell, D. A.; Alvarez, R.; Blixt, O.; Taylor, M. E.; Weis, W. I.; Drickamer, K., Structural basis for distinct ligand-binding and targeting properties of the receptors DC-SIGN and DC-SIGNR. Nat. Struct. Mol. Biol. 2004, 11 (7), 591598.
39. Pohlmann, S.; Soilleux, E. J.; Baribaud, F.; Leslie, G. J.; Morris, L. S.; Trowsdale, J.; Lee, B.; Coleman, N.; Doms, R. W., DCSIGNR, a DC-SIGN homologue expressed in endothelial cells, binds to human and simian immunodeficiency viruses and activates infection in trans. Proc. Natl. Acad. Sci. U.S.A. 2001, 98 (5), 2670-2675.

40. Guo, Y.; Bruce Turnbull, W.; Zhou, D., Probing Multivalent Protein-Carbohydrate Interactions by Quantum Dot-Forster Resonance Energy Transfer. Methods Enzymol. 2018, 598, 71-100.

41. Jarvis, C. M.; Zwick, D. B.; Grim, J. C.; Alam, M. M.; Prost, L. R.; Gardiner, J. C.; Park, S.; Zimdars, L. L.; Sherer, N. M.; Kiessling, L. L., Antigen structure affects cellular routing through DC-SIGN. Proc. Natl. Acad. Sci. U.S.A. 2019, 116 (30), 14862-14867.

42. Geijtenbeek, T. B. H.; Gringhuis, S. I., Signalling through C-type lectin receptors: shaping immune responses. Nat. Rev. Immunol. 2009, 9 (7), 465-479.

43. Gringhuis, S. I.; den Dunnen, J.; Litjens, M.; van der Vlist, M.; Geijtenbeek, T. B. H., Carbohydrate-specific signaling through the DC-SIGN signalosome tailors immunity to Mycobacterium tuberculosis, HIV-1 and Helicobacter pylori. Nat. Immunol. 2009, 10 (10), 10811088 .

44. van Kooyk, Y.; Rabinovich, G. A., Protein-glycan interactions in the control of innate and adaptive immune responses. Nat. Immunol. 2008, 9 (6), 593-601.

45. Lee, J. H.; Ozorowski, G.; Ward, A. B., Cryo-EM structure of a native, fully glycosylated, cleaved HIV-1 envelope trimer. Science 2016, 351 (6277), 1043-1048.

46. Stewart-Jones, G. B. E.; Soto, C.; Lemmin, T.; Chuang, G. Y.; Druz, A.; Kong, R.; Thomas, P. V.; Wagh, K.; Zhou, T. Q.; Behrens, A. J.; Bylund, T.; Choi, C. W.; Davison, J. R.; Georgiev, I. S.; Joyce, M. G.; Do Kwon, Y.; Pancera, M.; Taft, J.; Yang, Y. P.; Zhang, B. S.; Shivatare, S. S.; Shivatare, V. S.; Lee, C. C. D.; Wu, C. Y.; Bewley, C. A.; Burton, D. R.; Koff, W. C.; Connors, M.; Crispin, M.; Baxa, U.; Korber, B. T.; Wong, C. H.; Mascola, J. R.; Kwong, P. D., 1 Trimeric HIV-1-Env Structures Define Glycan Shields from Clades A, B, and G. Cell 2016, 165 (4), 813-826.

47. Dubertret, B.; Calame, M.; Libchaber, A. J., Single-mismatch detection using gold-quenched fluorescent oligonucleotides. Nat. Biotech. 2001, 19 (4), 365-370.

48. Susumu, K.; Uyeda, H. T.; Medintz, I. L.; Pons, T.; Delehanty, J. B.; Mattoussi, H., Enhancing the stability and biological functionalities of quantum dots via compact multifunctional ligands. J. Am. Chem. Soc. 2007, 129 (45), 13987-13996.

49. Zhou, D.; Bruckbauer, A.; Ying, L. M.; Abell, C.; Klenerman, D., Building three-dimensional surface biological assemblies on the nanometer scale. Nano Lett. 2003, 3 (11), 1517-1520.

50. Ramos-Soriano, J.; Reina, J. J.; Illescas, B. M.; de la Cruz, N.; Rodriguez-Perez, L.; Lasala, F.; Rojo, J.; Delgado, R.; Martin, N., Synthesis of Highly Efficient Multivalent Disaccharide/ 60 Fullerene Nanoballs for Emergent Viruses. J. Am. Chem. Soc. 2019, 141 (38), 15403-15412.

51. Wang, W. L.; Guo, Y.; Tiede, C.; Chen, S. Y.; Kopytynski, M.; Kong, Y. F.; Kulak, A.; Tomlinson, D. R.; Chen, R. J.; McPherson, M.; Zhou, D. J., Ultraefficient Cap-Exchange Protocol To Compact Biofunctional Quantum Dots for Sensitive Ratiometric Biosensing and Cell Imaging. ACS Appl. Mater. Interfaces 2017, 9 (18), 15232-15244.

52. Burns, J. A.; Butler, J. C.; Moran, J.; Whitesides, G. M., Selective Reduction of Disulfides by Tris(2-Carboxyethyl)phosphine. $J$. Org. Chem. 1991, 56 (8), 2648-2650.

53. Love, J. C.; Estroff, L. A.; Kriebel, J. K.; Nuzzo, R. G.; Whitesides, G. M., Self-assembled monolayers of thiolates on metals as a form of nanotechnology. Chem. Rev. 2005, 105 (4), 1103-1169.

54. Hill, H. D.; Millstone, J. E.; Banholzer, M. J.; Mirkin, C. A., The Role Radius of Curvature Plays in Thiolated Oligonucleotide Loading on Gold Nanoparticles. ACS Nano 2009, 3 (2), 418-424.

55. Jennings, T. L.; Singh, M. P.; Strouse, G. F., Fluorescent lifetime quenching near $\mathrm{d}=1.5 \mathrm{~nm}$ gold nanoparticles: Probing NSET validity. J. Am. Chem. Soc. 2006, 128 (16), 5462-5467.

56. Pons, T.; Medintz, I. L.; Sapsford, K. E.; Higashiya, S.; Grimes, A. F.; English, D. S.; Mattoussi, H., On the quenching of semiconductor quantum dot photoluminescence by proximal gold nanoparticles. Nano Lett. 2007, 7 (10), 3157-3164. 
57. Seferos, D. S.; Giljohann, D. A.; Hill, H. D.; Prigodich, A. E.; Mirkin, C. A., Nano-flares: Probes for transfection and mRNA detection in living cells. J. Am. Chem. Soc. 2007, 129 (50), 15477-15479.

58. Song, S. P.; Liang, Z. Q.; Zhang, J.; Wang, L. H.; Li, G. X.; Fan, C. H., Gold-Nanoparticle-Based Multicolor Nanobeacons for Sequence-Specific DNA Analysis. Angew. Chem. Int. Ed. 2009, 48 (46), 8670-8674.

59. Zhang, H. Y.; Feng, G. Q.; Guo, Y.; Zhou, D. J., Robust and specific ratiometric biosensing using a copper-free clicked quantum dot-DNA aptamer sensor. Nanoscale 2013, 5 (21), 10307-10315.

60. Chung, N. P.; Breun, S. K.; Bashirova, A.; Baumann, J. G.; Martin, T. D.; Karamchandani, J. M.; Rausch, J. W.; Le Grice, S. F.; Wu, L.; Carrington, M.; Kewalramani, V. N., HIV-1 transmission by dendritic cell-specific ICAM-3-grabbing nonintegrin (DC-SIGN) is regulated by determinants in the carbohydrate recognition domain that are absent in liver/lymph node-SIGN (L-SIGN). J. Biol. Chem. 2010, 285 (3), 2100-2112.

61. Feinberg, H.; Mitchell, D. A.; Drickamer, K.; Weis, W. I., Structural basis for selective recognition of oligosaccharides by DCSIGN and DC-SIGNR. Science 2001, 294 (5549), 2163-2166.

62. Song, L.; Ho, V. H. B.; Chen, C.; Yang, Z. Q.; Liu, D. S.; Chen, R. J.; Zhou, D. J., Efficient, pH-Triggered Drug Delivery Using a pH-Responsive DNA-Conjugated Gold Nanoparticle. Adv. Healthcare Mater. 2013, 2 (2), 275-280.
63. Hondow, N.; Brydson, R.; Wang, P. Y.; Holton, M. D.; Brown, M. R.; Rees, P.; Summers, H. D.; Brown, A., Quantitative characterization of nanoparticle agglomeration within biological media. $J$. Nanopart. Res. 2012, 14 (7), article no: 977.

64. Williams, J. A.; Gui, L.; Hom, N.; Mileant, A.; Lee, K. K., Dissection of Epitope-Specific Mechanisms of Neutralization of Influenza Virus by Intact IgG and Fab Fragments. J. Virol. 2018, 92 (6), article no: e02006-17.

65. Yang, M. L.; Chen, Y. H.; Wang, S. W.; Huang, Y. J.; Leu, C. H.; Yeh, N. C.; Chu, C. Y.; Lin, C. C.; Shieh, G. S.; Chen, Y. L.; Wang, J. R.; Wang, C. H.; Wu, C. L.; Shiau, A. L., Galectin-1 Binds to Influenza Virus and Ameliorates Influenza Virus Pathogenesis. J. Virol. 2011, 85 (19), 10010-10020.

66. Watson, A.; Phipps, M. J. S.; Clark, H. W.; Skylaris, C. K.; Madsen, J., Surfactant Proteins A and D: Trimerized Innate Immunity Proteins with an Affinity for Viral Fusion Proteins. J. Innate Immun. 2019, 11 (1), 13-28.

67. Watanabe, Y. A., J.D.; Wrapp, D.; McLellan, J.S.; Crispin, M., Site-specific glycan analysis of the SARS-CoV-2 spike. Science 2020, 10.1126/science.abb9983.

68. Lapitan, L. D. S.; Xu, Y. H.; Guo, Y.; Zhou, D. J., Combining magnetic nanoparticle capture and poly- enzyme nanobead amplification for ultrasensitive detection and discrimination of DNA single nucleotide polymorphisms. Nanoscale 2019, 11 (3), 1195-1204. 